Award Number: W81XWH-13-1-0164

TITLE: Obesity Exposure Across the Lifespan on Ovarian Cancer Pathogenesis

PRINCIPAL INVESTIGATOR: Victoria Bae-Jump, M.D., Ph.D.

CONTRACTING ORGANIZATION:

The University of North Carolina at Chapel Hill

Chapel Hill, NC 27599-7295

REPORT DATE: June 2014

TYPE OF REPORT: Annual

PREPARED FOR: U.S. Army Medical Research and Materiel Command Fort Detrick, Maryland 21702-5012

DISTRIBUTION STATEMENT: Approved for Public Release; Distribution Unlimited

The views, opinions and/or findings contained in this report are those of the author(s) and should not be construed as an official Department of the Army position, policy or decision unless so designated by other documentation. 


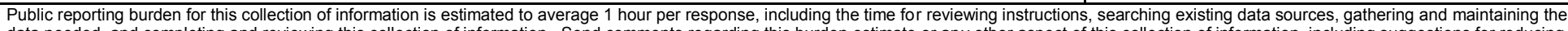

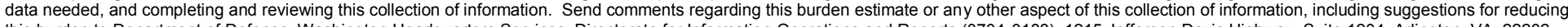

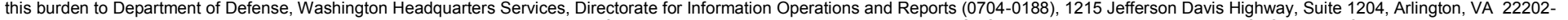

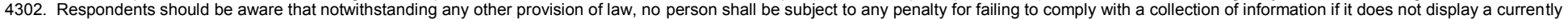
valid OMB control number. PLEASE DO NOT RETURN YOUR FORM TO THE ABOVE ADDRESS.

\begin{tabular}{|l|l|l|l}
\hline 1. REPORT DATE 1 Jun 2014 & 2. REPORT TYPE & 3. DATES COVERED
\end{tabular}

\section{TITLE AND SUBTITLE} Annual

Obesity Exposure Across the Lifespan on Ovarian Cancer Pathogenesis 01 June $2013-31$ May 2014

5b. GRANT NUMBER

W81XWH-13-1-0164

5c. PROGRAM ELEMENT NUMBER

\section{AUTHOR(S)}

Victoria Bae-Jump, M.D., Ph.D.

Betty Diamond

5d. PROJECT NUMBER

5e. TASK NUMBER

5f. WORK UNIT NUMBER

E-Mail: Victoria.Bae-Jump@unchealth.unc.edu 7. PERFORMING ORGANIZATION NAME(S) AND ADDRESS(ES) AND ADDRESS(ES)

8. PERFORMING ORGANIZATION REPORT NUMBER

The University of North Carolina at Chapel Hill

Lineberger Comprehensive Cancer Center

450 West Drive

CB 7295

Chapel Hill, NC 27599-2795

9. SPONSORING / MONITORING AGENCY NAME(S) AND ADDRESS(ES)

U.S. Army Medical Research and Materiel Command

Fort Detrick, Maryland 21702-5012

10. SPONSOR/MONITOR'S ACRONYM(S)

11. SPONSOR/MONITOR'S REPORT NUMBER(S)

12. DISTRIBUTION / AVAILABILITY STATEMENT

Approved for Public Release; Distribution Unlimited

\section{SUPPLEMENTARY NOTES}

\section{ABSTRACT}

Obesity is associated with increased risk and worse outcomes for ovarian cancer (OC). We theorize that the metabolic effects of obesity may play a contributing role in the pathogenesis of $\mathrm{OC}$ and lead to biologically different cancers than those that arise in normal weight women. We also posit that the timing and length of the obesity exposure may be critical in the development of obesity-driven OCs. We have demonstrated that adulthood exposure to obesity can promote tumor progression, as evidenced by a tripling in tumor size, in the $\mathrm{KpB}$ mouse model of serous $\mathrm{OC}$. The ovarian tumors that arose in the obese mice were genomically and metabolically different from those that arose in non-obese mice. To expand on this work, we assessed in utero, adolescent and adulthood exposure to obesity as well as cross-over between these timeframes in the KpB mice. Longer exposure to obesity resulted in greater tumor weight and shorter tumor latency, especially in diet exposures that included in utero exposure to obesity. Using The Cancer Genome Atlas database, we compared the gene expression between OCs from normal weight versus overweight/obese women. Metabolically relevant alterations in gene expression were found in relationship to BMI status among serous OCs.

\section{SUBJECT TERMS}

ovarian cancer, obesity, mTOR pathway, mouse model, metabolomics, genomics, The Cancer Genome Atlas Project

16. SECURITY CLASSIFICATION OF:

\begin{tabular}{c|c|c}
\hline a. REPORT & b. ABSTRACT & c. THIS PAGE \\
$U$ & $U$ & $U$ \\
\hline
\end{tabular}

17. LIMITATION OF ABSTRACT

UU
18. NUMBER OF PAGES

37 19a. NAME OF RESPONSIBLE PERSON USAMRMC 19b. TELEPHONE NUMBER (include area code) 


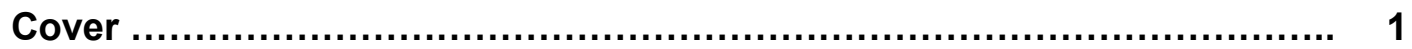

SF298.

Table of Contents...................................................................... $\quad 3$

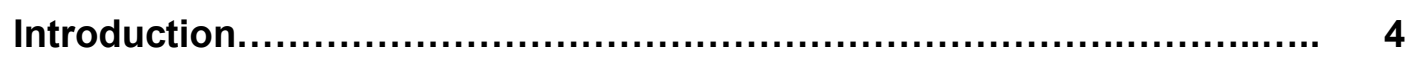

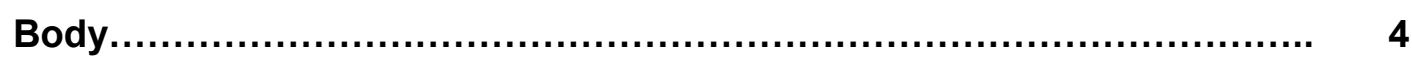

Key Research Accomplishments................................................. $\quad 9$

Reportable Outcomes............................................................. 11

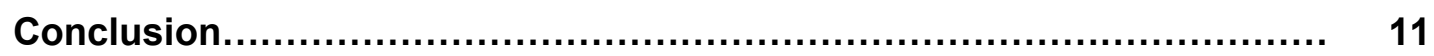

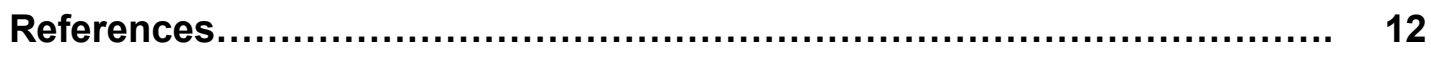

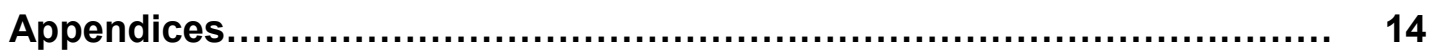




\section{INTRODUCTION}

Epithelial ovarian cancer is one of the most deadly cancers with an overall 5-year survival of only $30-40 \%$. Increasing evidence suggests that obesity is a significant risk factor for ovarian cancer and is associated with worse outcomes for this disease (1-14). Less is known of the impact of the timing of the obesity exposure, but some epidemiological studies suggest that adolescent exposure to obesity bears the greatest increased risk for ovarian cancer development $(12,15)$. We hypothesize that the metabolic and endocrine effects of obesity play a role in the carcinogenesis of ovarian cancer and invariably lead to biologically distinct cancers than those that arise in leaner women, possibly through aberrant modulation of mTOR signaling in an obesity-specific mechanism. An understanding of the relationship between obesity across the lifespan of a woman, and mTOR activation in ovarian cancer pathogenesis has yet to be explored and makes this proposal novel. This translational proposal will address this gap in knowledge by investigating the impact of the timing of the obesity exposure in vivo and in vitro using a novel serous ovarian tumor murine model and in ovarian cancer tumors from obese and non-obese women via interrogation of The Cancer Genome Atlas (TCGA) Project database. We postulate that in utero and adolescent exposure to obesity will increase vulnerability to ovarian cancer, and this will be manifested in obesity-specific mTOR hyperactivation and its downstream effects on enhanced proliferation and an advantageous metabolic profile.

BODY

Table 1. Diet-induced metabolic characteristics in non-obese and obese KpB mice.

Task 1 (Aim 1): To compare tumor latency and growth

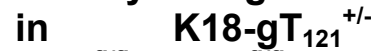
$; p 53^{\mathrm{fl} / \mathrm{fl}} ; \mathrm{Brca1}^{\mathrm{fl} / \mathrm{fl}}$

(KpB) mice exposed to a high fat diet at different time points across the lifespan,

\begin{tabular}{|l|l|l|l|}
\hline & Non-Obese & Obese & p-value \\
\hline Weight (gms) & $31.14 \pm 5.26$ & $50.71 \pm 16.73$ & $\mathrm{p}=0.0003$ \\
\hline Glucose (mg/dl) & $186.81 \pm 26.99$ & $214.38 \pm 58.11$ & $\mathrm{p}=0.053$ \\
\hline \% Fat & $3.28 \pm 1.51$ & $19.58 \pm 7.88$ & $\mathrm{p}=0.00001$ \\
\hline \% Lean & $22.89 \pm 2.11$ & $28.66 \pm 5.24$ & $\mathrm{p}=0.0006$ \\
\hline
\end{tabular}

$\mathrm{N}=14$ mice per group. Mean $\pm \mathrm{SD}$. \% Fat or \% lean = each mass/total body mass as measured by MRI.

including in utero,

adolescence and adulthood.

We have previously described a unique serous ovarian cancer mouse model that specifically and somatically deletes the tumor suppressor genes, Brca1 and p53, and inactivates the retinoblastoma ( $\mathrm{Rb}$ ) proteins in adult ovarian surface epithelial cells (KpB mouse model) $(45,46)$. Subsequently, $\mathrm{KpB}$ mice were subjected to a $60 \%$ caloriesderived from fat in a high fat diet (HFD) versus $10 \%$ calories from fat in a low fat diet (LFD) to induce diet-induced obesity ( $\mathrm{N}=14 /$ group) starting at 6 weeks of age and until sacrifice. After 8 months of exposure to the HFD or LFD, obese mice weighed significantly greater than non-obese mice $(p=0.003$, Table 1). There was no effect of HFD on non-fasted blood glucose levels or diabetes onset in KpB mice over the course of the diet (Table 1). Body composition was significantly altered in obese $\mathrm{KpB}$ mice compared to non-obese controls. Percent body fat was six-fold greater in obese mice (Table 1, $p=0.0001$ ), while percent lean mass increased by $25 \%$ $(p=0.0006$, Table 1$)$. The ovarian tumors were tripled in size in the obese mice as compared to non-obese mice (mean size of $3.7 \mathrm{~cm}^{2}$ versus $1.2 \mathrm{~cm}^{2}$, Figure 1, $\left.\mathrm{p}=0.0065\right)$. This suggests that obesity can promote tumor progression in the $\mathrm{KpB}$ mouse model of ovarian cancer.

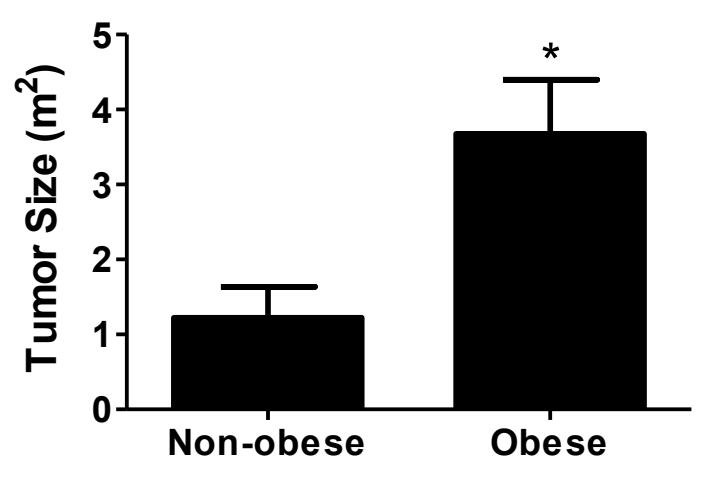

Figure 1. Obesity increases tumor size in KpB mice. KpB mice were fed low fat or high fat diets to induce obesity for 6 months during tumorigenesis. (A) Comparison of tumor size from non-obese and obese mice $(\mathrm{N}=14)$. These mice were sacrificed 6 months after ovarian tumor induction via injection of AdCre into the ovarian bursa cavity. For the calculation of tumor size, the greatest longitudinal diameter (length) and the greatest transverse diameter (width) were determined and multiplied $\left(\mathrm{m}^{2}\right)$. ${ }^{*} p=0.0065$. 
Obesity was found to induce genomic differences between the obese and non-obese ovarian tumors. 439 genes were found to be significantly up-regulated (417 genes) or down-regulated (22 genes) in the ovarian tumors from obese $\mathrm{KpB}$ mice versus non-obese mice $($ FDR $<0.2)$. Figure 2 is a heat map of 131 genes up- and down-regulated at a FDR $<0.1$. Many metabolically relevant genes were significantly upregulated in the ovarian tumors from the obese versus non-obese mice, such as lipocalin ( 2.7 fold), fatty acid amide hydrolase (2.7 fold), fatty acid 2-hydroxylase (2.2 fold), glycerol-3phosphate acyltransferase $(1.5$ fold $)$, protein phosphatase (1.2 fold), AMP deaminase 3 (1.6 fold), and protein kinase $C(1.7$ fold $)$. Arginase 1 was the most upregulated gene ( 7.3 fold) and plays a role in the urea cycle, tissue remodeling and inflammation. Other upregulated genes identified in the ovarian tumors from the obese mice were related to cell adhesion, including neurotrimin (2.2 fold) and desmoglein 1-alpha (2.0 fold). Increased expression of histone 1 (2.3 fold) and endothelin-1 (5.8 fold) were also associated with obesity in the $\mathrm{KpB}$ mouse model. Another gene upregulated 3 fold was ectonucleoside triphosphate diphosphohydrolase. Heparan sulfate (glucosamine) 3O-sulfotransferase 1 was upregulated 6 fold and regulates heparan sulfate production which is involved in developmental processes, angiogenesis, blood coagulation and tumor metastasis. The serotonin transporter solute carrier family 6 member 4 (Slc6a4)

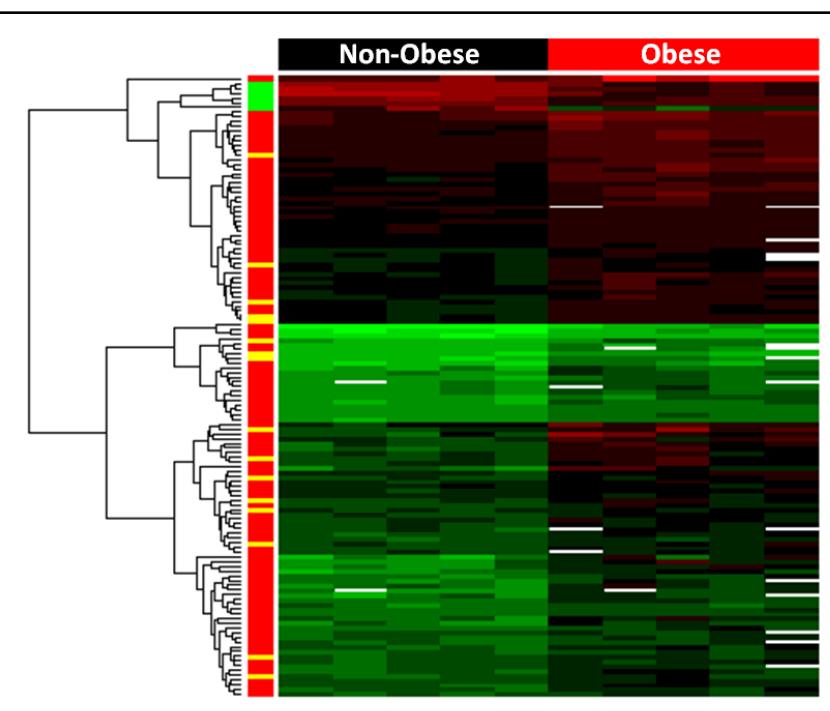

Figure 2. Genomic differences between ovarian tumors from obese versus non-obese KpB mice reveal alterations in metabolically relevant genes. Heat map representation of 131 genes significantly up- or down-regulated in ovarian tumors from obese versus non-obese $\mathrm{KpB}$ mice (FDR<0.1). Many metabolically relevant genes, such as lipocalin, fatty acid amide hydrolase, ectonucleoside triphosphate diphosphohydrolase, fatty acid 2-hydroxylase, glycerol-3-phosphate acyltransferase, protein phosphatase, protein kinase $\mathrm{C}$ and AMP deaminase 3 , were upregulated in obese tumors.

was upregulated 5.4 fold by obesity. Important downregulated genes included spermidine synthase, an enzyme in spermidine synthesis and thrombospondin 4, an extracellular glycoprotein known to have roles in cellular migration, adhesion, attachment and proliferation. In the ovarian tumors from the obese versus nonobese mice, DAVID functional annotation analysis revealed significant enrichment in "phospoholipid binding" (EASE score of 0.008), "regulation of apoptosis" (EASE score of 0.014), "lipid binding" (EASE score of 0.015), "endopeptidase activity" (EASE score of 0.03 ) and "cell-cell signaling" (EASE score of 0.44) for those identified genes.

Metabolic differences were also found between the ovarian tumors from obese and non-obese KpB mice. Principle component analysis defined a clear separation between obese and non-obese. Differentiating metabolites were selected with the criteria of the variable importance in the projection (VIP) value $>1$ and $p$ value (Student's $t$ test) lower than 0.05 . Twenty metabolites were identified using this criteria, all of which were upregulated in the ovarian tumors of the non-obese versus obese KpB mice (Table 2).

Metabolites involved in inflammatory signaling and protein/collagen metabolism were down-regulated in the ovarian tumors of obese mice as compared to non-obese mice, including arginine $(p=0.0268), N$ glycylproline $(p=0.0043)$ and 3-amino-2-piperidone $(p=0.0099)$. Components and markers of oxidative stress were also downregulated in the tumors from obese mice: glutathione $(p=0.0313)$, oxidized glutathione $(p=0.0047)$, gluconolactone $(p=0.0311)$ and 8-hydroxy-deoxyguanosine $(p=0.0230)$. Lower levels of nucelotides (i.e. cytidine $(p=0.0122$ and $p=0.0424)$, cytosine $(p=0.0158)$, guanosine diphosphate (GDP, $p=0.0404)$ ) and adenosine monophosphate (AMP, $p=0.0257)$ were detected with obesity. The serotonin metabolite, 5-hydroxyindoleacetic acid (5HIAA, $p=0.0498)$, and the catecholamine metabolites, vanillactic acid $(p=0.0079)$ and phenylethanolamine $(p=0.0446)$, were found to be lower in the ovarian tumors of obese versus non-obese mice. Glutamate $(p=.0318), N$-acetylaspartic acid $(p=0.0059)$ and succinic acid $(p=0.0465)$ are involved in energy metabolism, and were decreased in the ovarian tumors of obese $\mathrm{KpB}$ mice as compared to their non-obese counterparts. LysoPC $(16: 1(9 Z))(p=0.0205)$, a lysophospholipid, and the metabolite of a toxic intermediate, inodxyl glucuronide $(p=0.0439)$, were also lower in the ovarian tumors from obese animals. 
Table 2. Metabolic alterations in tumors from non-obese and obese $\mathrm{KpB}$ mice.

\begin{tabular}{|c|c|c|c|c|c|}
\hline Compound name & VIP $^{\mathbf{a}}$ & $p^{b}$ & $\begin{array}{c}\text { Fold Change } \\
\text { (non- }^{\text {obese/obese) }}\end{array}$ & $\begin{array}{l}\text { Analysis } \\
\text { method }\end{array}$ & $\begin{array}{l}\text { Identification } \\
\text { Method }^{\mathrm{e}}\end{array}$ \\
\hline N-Glycylproline & 2.27 & 0.0043 & 1.95 & LC-ES+ & Std \\
\hline Oxidized glutathione & 2.25 & 0.0047 & 3.45 & LC-ES+ & Std \\
\hline N-Acetylaspartic acid & 2.22 & 0.0059 & 2.31 & LC-ES- & HMDB \\
\hline Vanillactic acid & 2.17 & 0.0079 & 2.23 & LC-ES+ & HMDB \\
\hline 3-amino-2-piperidone & 2.14 & 0.0099 & 1.75 & GCTOF & NIST \\
\hline Cytidine & 2.10 & 0.0122 & 4.52 & LC-ES+ & Std \\
\hline Cytosine & 2.05 & 0.0158 & 4.11 & LC-ES+ & Std \\
\hline LysoPC(16:1(9Z)) & 1.99 & 0.0205 & 1.83 & LC-ES+ & HMDB \\
\hline 8-Hydroxy-deoxyguanosine & 1.97 & 0.0230 & 2.45 & LC-ES+ & HMDB \\
\hline Adenosine monophosphate & 1.94 & 0.0257 & 1.61 & LC-ES- & HMDB \\
\hline Arginine & 1.93 & 0.0268 & 1.93 & LC-ES+ & Std \\
\hline Gluconolactone & 1.89 & 0.0311 & 2.97 & LC-ES+ & Std \\
\hline Glutathione & 1.89 & 0.0313 & 3.10 & LC-ES+ & Std \\
\hline Glutamate & 1.89 & 0.0318 & 1.52 & GCTOF & Std \\
\hline Guanosine diphosphate & 1.82 & 0.0404 & 2.39 & LC-ES- & HMDB \\
\hline Cytidine & 1.81 & 0.0424 & 4.97 & GCTOF & NIST \\
\hline Inodxyl glucuronide & 1.80 & 0.0439 & 3.05 & LC-ES+ & HMDB \\
\hline Phenylethanolamine & 1.80 & 0.0446 & 1.69 & GCTOF & NIST \\
\hline Succinic acid & 1.78 & 0.0465 & 1.90 & GCTOF & Std \\
\hline 5-Hydroxyindoleacetic acid & 1.76 & 0.0498 & 1.85 & LC-ES+ & HMDB \\
\hline \multicolumn{6}{|c|}{$\begin{array}{l}\text { a variable importance in the projection (VIP) was obtained from OPLS-DA with a threshold of 1.0; } \\
{ }^{b} p \text { value was calculated from Student's } t \text { Test; }{ }^{\mathrm{c}} \text { Fold change with a value larger than } 1 \text { indicates a } \\
\text { relatively higher concentration in tumors from non-obese (low fat diet-fed) KpB mice, while a value } \\
\text { less than } 1 \text { means a relatively lower concentration as compared to tumors from obese (high fat diet- } \\
\text { fed) KpB mice. }{ }^{\mathrm{e}} \text { The metabolites were identified by in-house library (Std), NIST library (NIST) or } \\
\text { HMBD database (HMDB). }\end{array}$} \\
\hline
\end{tabular}

To further expand on this work, the $\mathrm{KpB}$ ovarian cancer mouse model was used to assess the tumor promoting effect of high fat diet (HFD)-diet-induced obesity on tumor initiation and promotion amongst different obesity exposures across the lifespan. KpB mice were placed on a LFD or a HFD at different time points during their lifespan, including in utero, adolescence and adulthood. Cross-over diet study design was employed to examine if weight loss by switching from a HFD to a LFD reverses elevated risk associated
Table 3. Diet Study using the KpB ovarian cancer mouse model to identify relevant windows of susceptibility to obesity-induced risk. The effect of obesity on tumor promotion in mice made obese by high fat diet versus non-obese mice at relevant periods of vulnerability including in utero, adolescence and adulthood as well as combinations of these exposures were explored.

\begin{tabular}{c|c|c|c|}
\hline Group & $\begin{array}{c}\text { In utero } \\
\text { exposure }\end{array}$ & $\begin{array}{c}\text { Adolescent } \\
\text { exposure }\end{array}$ & $\begin{array}{c}\text { Adulthood } \\
\text { exposure }\end{array}$ \\
\hline A & LFD & LFD & LFD \\
\hline B & LFD & LFD & HFD \\
\hline C & LFD & HFD & HFD \\
\hline D & LFD & HFD & LFD \\
\hline E & HFD & HFD & HFD \\
\hline F & HFD & HFD & LFD \\
\hline $\mathbf{G}$ & HFD & LFD & LFD \\
\hline H & HFD & LFD & HFD \\
\hline
\end{tabular}


with obesity. Eight different diet exposures were examined, as depicted in Table 3.

Tumor weight (grams) was found to be larger when comparing group A (no exposure to a HFD; LFD in utero + adolescence + adulthood) to groups $E$ (HFD in utero + adolescence + adulthood), F (HFD in utero + HFD in adolescence + LFD in adulthood) and $\mathrm{H}$ (HFD in utero + LFD in adolescence + HFD in adulthood) (Figure 3A). Tumor latency was found to be shorter when comparing group A (no exposure to a HFD; LFD in utero + adolescence + adulthood) to groups $F$ (HFD in utero + HFD in adolescence + LFD in adulthood) and $\mathrm{H}$ (HFD in utero + LFD in adolescence + HFD in adulthood) (Figure 3B). Common to all the groups that had a statistically significant difference in either tumor weight or tumor latency compared to group A (no exposure to a HFD) was (1) in utero exposure to a HFD and (2) exposure to a HFD for at least two different timeframes across the lifespan of the mouse. This data is based on 6-8 mice per group; however, all of the data is not complete with an expected 12-15 mice per group at the completion of the study. This preliminary data does suggest that longer exposure to a HFD results in greater tumor weight and shorter tumor latency.

The weight of the mice was also greater in the groups with longer exposure to the HFD. When compared to group A (LFD in utero + adolescence + adulthood), groups B (LFD in utero + LFD in adolescence + HFD in adulthood), C (LFD in utero + HFD in adolescence + HFD in adulthood), E (HFD in utero + HFD in adolescence + HFD in adulthood) and $\mathrm{H}$ (HFD in utero + LFD in adolescence + HFD in adulthood) (Figure 4). Common to all the groups that had a statistically significant difference in mouse weight compared to group A (no exposure to a HFD) was adulthood exposure to a HFD. There were no significant changes in blood glucose levels among the eight groups (data not shown). The ovarian tumors from each of these groups has been frozen for gene expression profiling and metabolomic comparative analysis in the upcoming year.

Task 2 (Aim 2): To determine if PI3K/Akt/mTOR pathway hyperactivation and alterations in glucose metabolism are related to obesitydriven cancers in the $\mathrm{KpB}$ ovarian cancer mouse model.

We are waiting to sacrifice the rest of the $\mathrm{KpB}$ mice in each of the diet groups before we can proceed with this aim. As part of this aim, ovarian tumors from the $\mathrm{KpB}$ mice that were exposed to obesity initiated in utero versus adolescence versus adulthood versus combinations of these exposures will undergo Western immunoblotting and immunohistochemical analysis to assess for

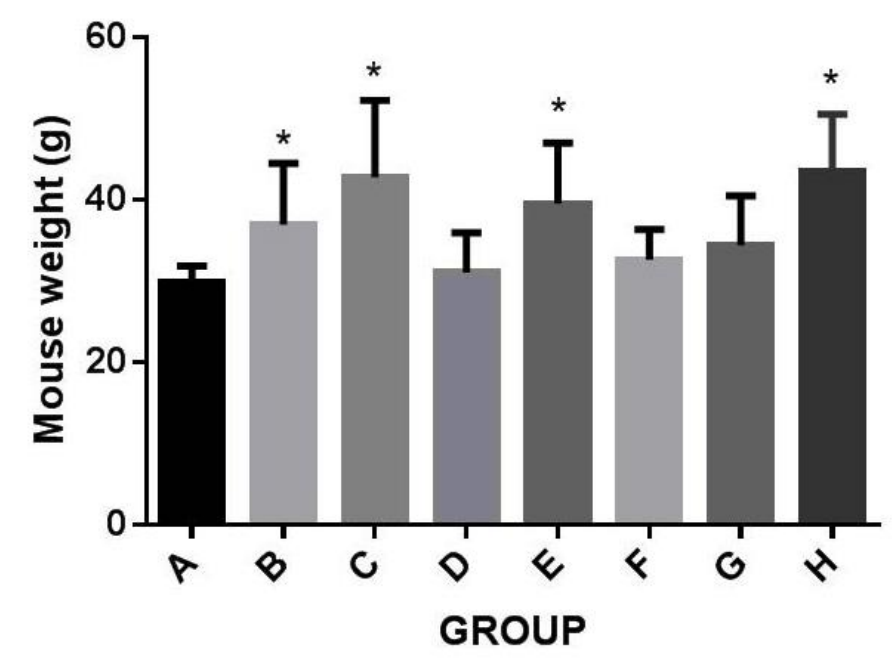

Figure 4. Exposure to a HFD increases the weight of the KpB mice. KpB mice were placed on a LFD or a HFD at different time points during their lifespan, including in utero, adolescence and adulthood. (see Table 3 for description of groups) $\left({ }^{*} p<0.05\right)$ 
differences in the phosphorylated and/or total forms of the downstream target proteins of the IGF-1R and $\mathrm{PI} 3 \mathrm{~K} / \mathrm{Akt} / \mathrm{mTOR}$ pathway. A subset of these ovarian cancer tumors will be used for primary culture to assess for secretion of growth factors associated with ovarian carcinogenesis (i.e. IGF-1) and perturbations in glucose metabolism as evaluated by ELISA and metabolic assays, respectively.

Task 3 (Aim 3): To assess cross-species differences of the gene expression profiles of ovarian cancer tumors from obese and non-obese women and KpB mice, using the relevant tumor data from The Cancer Genome Atlas (TCGA) Project database.

From the TCGA database, we collected expression measurements for 12,042 genes from the platform (BI_HT_HG-U133A level 3 data) for differential gene expression analysis among human serous OC samples. The detailed information of the data processing, quality control and normalization can be found on the TCGA website. To identify significantly differentially expressed genes associated with BMI, we applied linear modeling for responses as gene expression and covariates as 5 principal components (PCs) (from gene expression data to control potential batch effects), clinical stage, grade, age, race, residual tumor and BMI status (0 if normal $\mathrm{BMI}<25 ; 1$ if overweight $\mathrm{BMI} \geq 25$ ). Appropriate false discovery rates (FDR) were controlled. With the obtained genes that were significantly associated with BMI status, we conducted functional clustering analysis on the website of The Database for Annotation, Visualization and Integrated Discovery (DAVID). In addition, we applied hierarchical clustering analysis to generate a representative heatmap. The Chi-square test was used to compare BMI among different clusters of samples. A comparison of the demographics between the ovarian cancer tumors from normal weight $(B M I<25)$ and overweight/obese women $(B M I \geq 25)$ can be found in Table 4.

347 genes were found to be significantly up- or down-regulated with BMI status (BMI < 25 versus $\mathrm{BMI} \geq 25$ ) among the serous ovarian tumors (q-value $<\quad 0.1)$ including metabolically relevant genes (Supplemental Tables 1 and 2). Genes that were down-regulated included the prolactin receptor (3.6 fold) and apolipoprotein B mRNA editing enzyme (3.1 fold), among others. Genes that were up-regulated included mitogenactivated protein kinase Table 4. Comparison of the demographics between the ovarian cancer tumors from normal weight and overweight/obese women.

\begin{tabular}{|c|c|c|}
\hline & $\begin{array}{c}\text { BMI }<25 \text { (Normal } \\
\text { Weight) } \\
(\mathrm{N}=99)\end{array}$ & $\begin{array}{c}\text { BMI } \geq 25 \\
\text { (Overweight/Obese) } \\
(\mathrm{N}=138)\end{array}$ \\
\hline Age (mean) & 57.9 & 59.4 \\
\hline $\begin{array}{r}\text { Race } \\
\text { White } \\
\text { Black } \\
\text { Other }\end{array}$ & $\begin{array}{c}89(90 \%) \\
5(5 \%) \\
5(5 \%)\end{array}$ & $\begin{array}{c}125(91 \%) \\
11(8 \%) \\
2(1 \%)\end{array}$ \\
\hline $\begin{aligned} & \text { Grade } \\
& 2 \\
& 3\end{aligned}$ & $\begin{array}{l}11(11 \%) \\
88(89 \%)\end{array}$ & $\begin{array}{c}12(9 \%) \\
126(91 \%)\end{array}$ \\
\hline $\begin{array}{ll}\text { Stage } & \\
& \text { I/II } \\
& \text { III/IV }\end{array}$ & $\begin{array}{c}2(2 \%) \\
97(98 \%)\end{array}$ & $\begin{array}{c}4(3 \%) \\
134(97 \%)\end{array}$ \\
\hline $\begin{array}{c}\text { Residual Disease } \\
\text { Optimal } \\
\text { Suboptimal }\end{array}$ & $\begin{array}{l}75(76 \%) \\
24(24 \%)\end{array}$ & $\begin{array}{l}99(72 \%) \\
39(28 \%)\end{array}$ \\
\hline
\end{tabular}

1 (3.3 fold), phospholipid

scramblase 1 (3.3 fold), carnitine/acylcarnitine translocase (3.2 fold), low density lipoprotein receptor-related protein 8 (apolipoprotein e receptor) (3.7 fold), apolipoprotein L3 (3.7 fold), apolipoprotein L1 (3.8 fold), lipoyltransferase 1 (4.2 fold), apolipoprotein L6 (4.2 fold) and the c-myc binding protein (4.1 fold). Many of these genes were related to the apolipoprotein pathway, particularly apolipoprotein $\mathrm{L}$ related genes. Apolipoprotein $L$ genes are members of the high density lipoprotein family and play a central role in cholesterol transport. Multiple genes involving the Ras oncogene family were up- and down-regulated when comparing normal weight versus overweight/obese women, including ras responsive element binding protein $1, \mathrm{RAB} 5 \mathrm{C}$, RREB1, ras-related GTP binding C, PAP1A, RAB7A, RAB31, RAB5A, and ras homolog family/member A. DAVID functional annotation analysis revealed significant enrichment in "protein transport" (Adjusted p-value for Benjamini $=5.5 \mathrm{E}-5$ ), "antigen processing and presentation of exogenous peptide antigen" (Adjusted pvalue for Benjamini $=1.3 \mathrm{E}-3$ ) and "pyrimidine ribonucleotide biosynthetic process" (Adjusted p-value for Benjamini $=3.6 \mathrm{E}-2$ ) for these identified genes . 
Initially, we used the 347 genes with q-value $<0.1$ to generate a heatmap, but the results of the hierarchical cluster analysis on these samples did not group them with a significantly different BMI distribution. Alternatively, we used the 175 genes with q-value $<0.05$ to generate a heatmap, which is presented in Figure 5 , where the row signifies gene expression and the column is clustering according to BMI (BMI $<25$ versus $B M I \geq 25$ ). If we specified two groups to cut a tree resulting from the results of the hierarchical cluster analysis on the samples, the two clusters of samples had no statistically significant difference in the distribution of BMI. However, if we specified three groups to cut a tree resulting from the results of the hierarchical cluster analysis, there were two pairs of clusters of samples with a significantly different distribution of BMI. Specifically, the first pair of clusters of samples (cluster 1 versus cluster 2 ) had sample proportions of subjects with BMI $\geq 25(0.65$, 0.33). For testing if the two proportions are significantly different, the obtained Chi-square statistics was $7.87, \mathrm{df}=1$ and $p$ value $=0.005$, suggesting that the two sample proportions are significantly different. The second pair of clusters of samples (cluster 3 versus cluster 2) had sample proportions of subjects with $\mathrm{BMI} \geq 25$ (0.61, 0.33). For testing if the two proportions are significantly different, the obtained Chi-square statistics was 11.36, $\mathrm{df}=1$ and $p$-value $=$ 0.00075 , suggesting that the two sample proportions are significantly different. In addition, there was significant difference in the proportions of women with a $\mathrm{BMI} \geq 25$ for cluster 1 and cluster $3(0.65,0.61)$. In summary, the analysis of the 175 gene set resulted in three sample clusters, with statistically significant differences in proportions of women with $\mathrm{BMI} \geq 25$ versus $\mathrm{BMI}$ $<25$ among these clusters. A summary of the genes in gene cluster 1 and 2 can be found in Table 5.

\section{KEY ACCOMPLISHMENTS \\ RESEARCH}

- The obese state can promote tumor progression in the $\mathrm{KpB}$ mouse model of ovarian cancer. Longer exposures to obesity had the greatest impact on tumor weight.

- Distinct metabolic and genomic differences were identified in ovarian

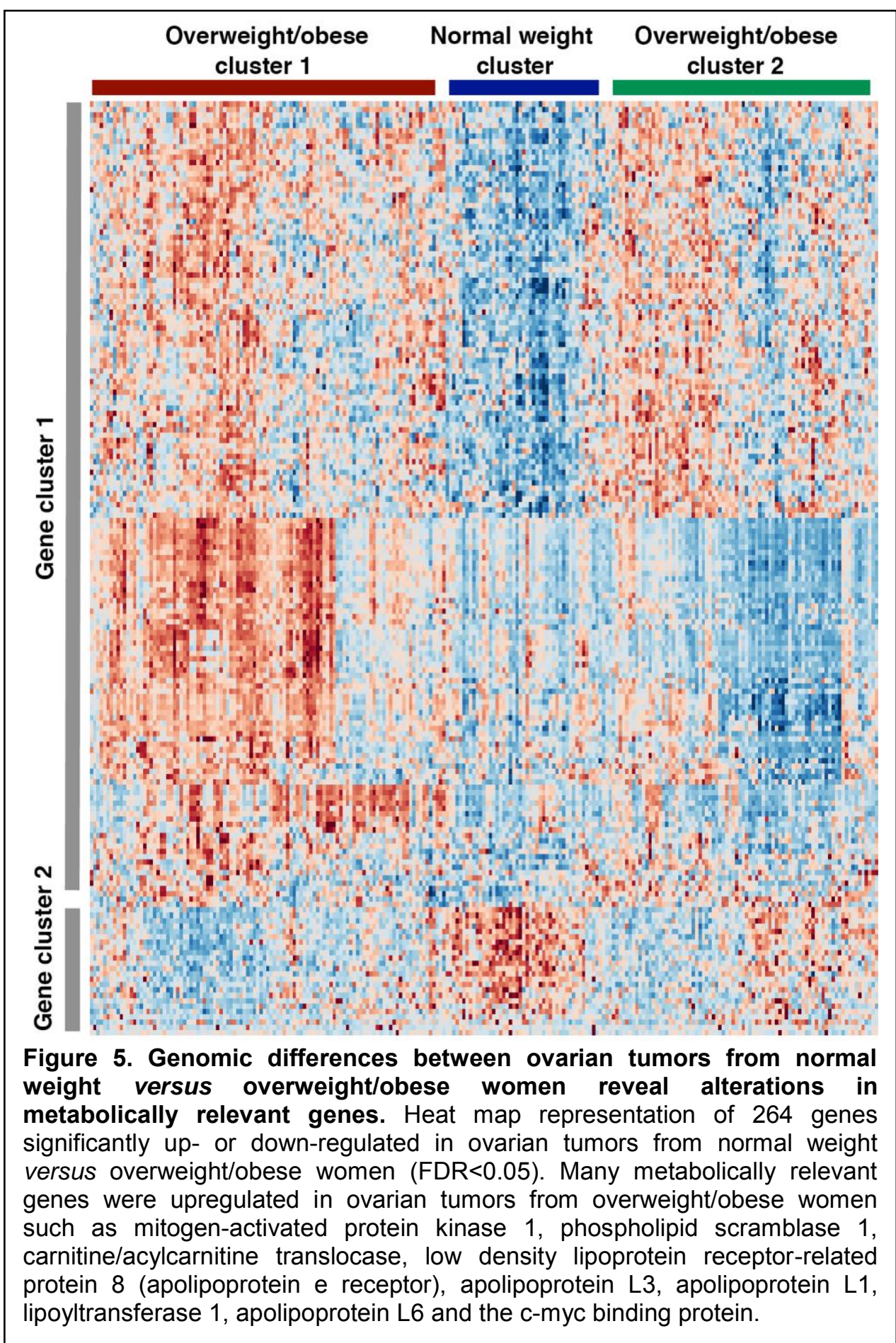


tumors that arose in KpB mice after adulthood exposure to a HFD versus a LFD, and many of these differences were related to metabolic relevant pathways.

- Metabolically relevant alterations in gene expression were found with increasing BMl among human serous ovarian cancers, using the TCGA database.

Table 5. Gene Clusters of the Ovarian Tumors from Normal Weight $(B M \mid<25)$ and Overweight/Obese Women (BMI 225 ).

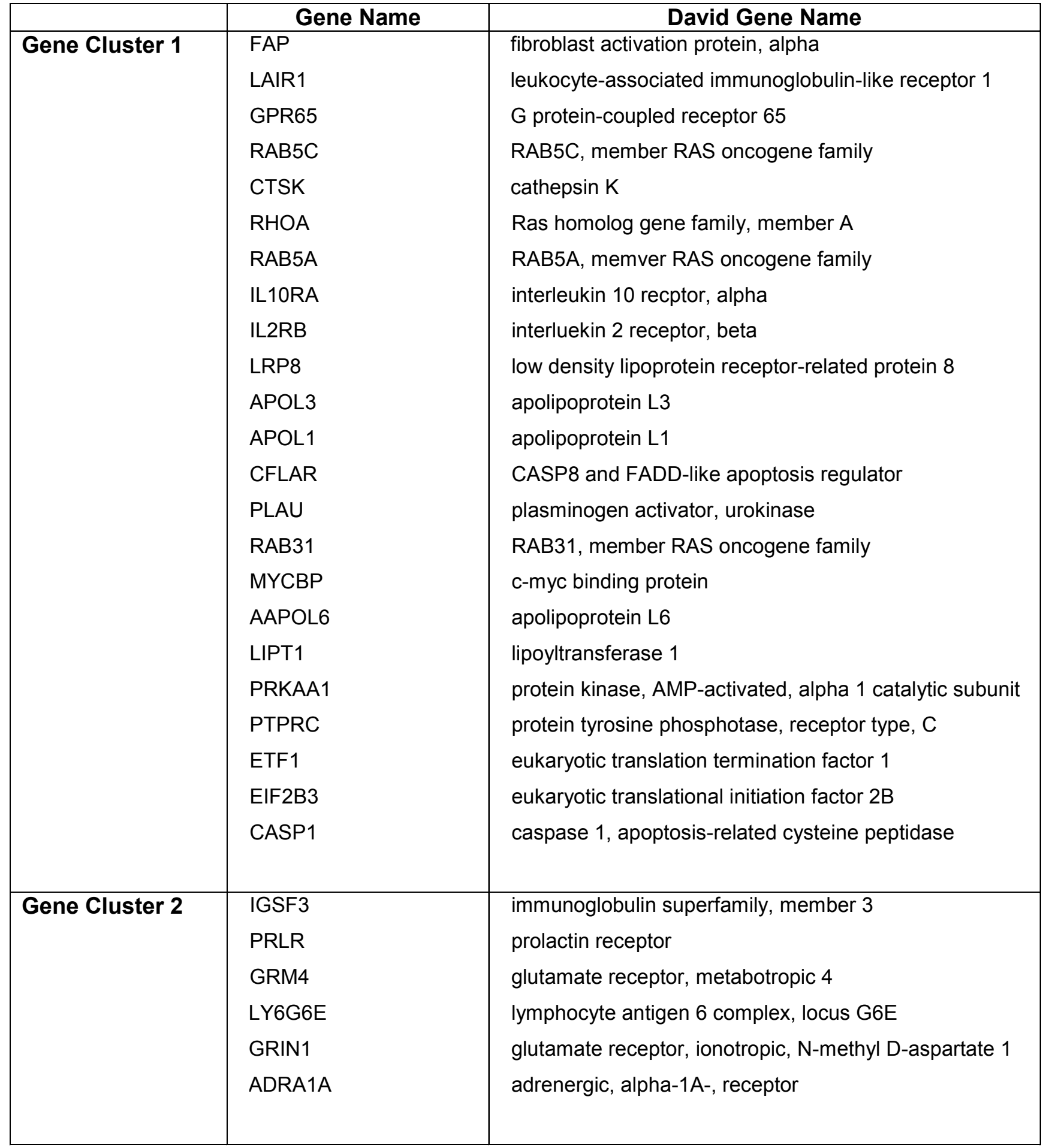




\section{REPORTABLE OUTCOMES}

\section{Abstracts presented:}

(1) Zhou, C, Zhong, Y, Du, X, Makowski, L, Jia, W and Bae-Jump, VL, Diet-induced obesity increases tumor aggressiveness in a genetically engineered mouse model of serous ovarian cancer, Oral Presentation by Dr. Bae-Jump at the 2013 Annual Meeting of the Society of Gynecologic Oncology.

\section{Manuscripts accepted:}

(1) Makowski, L, Zhou, C, Zhong, Y, Kuan, PF, Fan, Sampey, BP, Difurio, M and Bae-Jump, VL. Obesity increases tumor aggressiveness in a genetically engineered mouse model of serous ovarian cancer. Gynecologic Oncology, 133(1):90-7 (2014). PMID: 24680597

\section{Grants submitted:}

(1) $1 \mathrm{R} 01$ - AN:3701643

Obesity, Cation-Selective Transporters and Metformin in Endometrial Cancer

Co-Principal Investigator: Bae-Jump

$15 \%$ effort ( 1.8 calendar)

Mounting epidemiological and preclinical data suggest that metformin may be efficacious in endometrial cancer. However, two important questions that need to be addressed are: (1) Will metformin be universally effective in endometrial cancer or be more efficacious in the obese/insulin-resistant patient population? and (2) What role do transporters play in metformin uptake and action in the malignant endometrium? These fundamental questions will be explored in endometrial cancer, a disease driven by obesity and insulin resistance, using endometrial cancer mouse models and phase 0 and phase $2 / 3$ clinical trials in endometrial cancer patients.

(2) American Cancer Society/Research Scholar Grant

Obesity, Cation-Selective Transporters and Metformin in Endometrial Cancer

Co-Principal Investigator: Bae-Jump

$10 \%$ effort ( 1.2 calendar)

Mounting epidemiological and preclinical data suggest that metformin may be efficacious in endometrial cancer. However, two important questions that need to be addressed are: (1) Will metformin be universally effective in endometrial cancer or be more efficacious in the obese/insulin-resistant patient population? and (2) What role do transporters play in metformin uptake and action in the malignant endometrium? These fundamental questions will be explored in endometrial cancer, a disease driven by obesity and insulin resistance, using endometrial cancer mouse models and phase 0 and phase $2 / 3$ clinical trials in endometrial cancer patients.

\section{CONCLUSION}

Obesity is associated with increased risk and worse outcomes for OC, and alterations in $\mathrm{PI} 3 \mathrm{~K} / \mathrm{Akt} / \mathrm{mTOR}$ signaling may play a crucial role in this relationship with potential implications for prevention and improvement of outcomes for this disease. We and others have made significant progress investigating the effects of obesity on tumor cell growth, but an understanding of the interactions between obesity at specific vulnerable periods of development, $\mathrm{OC}$ and the PI3K/Akt/mTOR pathway is lacking. We theorize that the metabolic effects of obesity play a contributing role in the pathogenesis of OC and lead to phenotypically different cancers than those that arise in leaner women, potentially through hyperactivation of the mTOR kinase. We also posit that the timing and length of the obesity exposure is critical in the development of obesity-driven OCs. Although the PI3K/Akt/mTOR pathway is known to be separately important in obesity and $\mathrm{OC}$, the complex interplay between both of these disease entities on PI3k/Akt/mTOR signaling in OC has not been simultaneously assessed. Our multi-dimensional approach is innovative because utilizes several tools including a unique genetically engineered mouse model (GEMM), cell lines and patient samples to comprehensively interrogate the obesity-induced carcinogenesis signature through molecular, biochemical, genomic and metabolomic analysis. While the PI3K/AKT/mTOR pathway is a likely candidate pathway, the 
defined approach will identify additional genes and metabolites heretofore underappreciated in OC that are dependent upon windows of obesity exposure.

To first study the connection between metabolic status and OC, we capitalized upon the novel K18$\mathrm{gT}_{121}{ }^{+/-} ; \mathrm{p5}^{\mathrm{fl} / f \mathrm{l}} ; \mathrm{Brca}^{\mathrm{fl} / f \mathrm{l}}$ (KpB) OC genetically engineered mouse model (GEMM) in the obesity-susceptible FVB/N background. KpB mice were used to investigate the impact of obesity on OC pathogenesis and to test the effects of varying the timing and length of the obesity exposure across the lifespan, including in utero, adolescence and adulthood. Adulthood exposure to obesity in the KpB mouse model accelerated tumorigenesis. A tripling of tumor mass was found in $\mathrm{KpB}$ mice fed a high fat obesogenic diet versus a low fat control diet in our initial pilot study. Gene expression and metabolomic profiling indicated statistically significant differences between the ovarian tumors from the obese versus non-obese mice, including metabolically relevant pathways.

We expanded on this work to assess which windows of exposure to obesity are most important for increased vulnerability and progression of OC. Eight different diet exposures were examined, as depicted in Table 3. Longer exposure to a HFD resulted in greater tumor weight and shorter tumor latency, especially in diet exposures that included in utero exposure to obesity. The weight of the mice was also greater in the groups with longer exposure to a HFD, particularly those mice with adulthood exposure to a HFD. The ovarian tumors from each of these eight groups has been frozen for gene expression profiling and metabolomic comparative analysis as well as western blotting and immunohistochemical analysis for downstream targets of the PI3K/Akt/mTOR pathway. In the upcoming year, ovarian tumors from obese and non-obese mice will also be examined in primary culture as a means to interrogate the effects of the obesity exposure on mTOR hyperactivation and glucose metabolism, or pathways identified through genomics and metabolomics.

This proposal aims next to translate in vitro and preclinical studies into human relevance and explore the impact of obesity on human OC. Using The Cancer Genome Atlas (TCGA) database, we compared the gene expression between OCs from normal weight versus overweight/obese women. Metabolically relevant alterations in gene expression were found in relationship to BMI status among serous OCs, including multiple genes related to the apolipoprotein pathway. Apolipoproteins are proteins that bind lipids (oil-soluble substances such as fat and cholesterol) to form lipoproteins for transport through the lymphatic and circulatory systems. This will be pathway of interest for our future studies. In the upcoming year, cross-species gene expression comparisons of OC tumors derived from obese and non-obese women and KpB mice will be used as a strategy to identify obesity-dependent biomarkers and potential novel targets of treatment. Cross-species comparisons will lend strength to findings from either strategy, thus creating a powerful experimental paradigm. The proposed study design is innovative because the tools we will use such as the KpB mouse model and the TCGA database allows us to focus on the tumor/host interaction, especially in regards to obesity-driven effects. Through these complementary studies, we will advance the understanding of OC's metabolic and genomic responses to the tumor promoting environment of obesity and determine the impact of the timing and length of the obesity exposure on ovarian carcinogenesis.

\section{REFERENCES}

1. Delort L, Kwiatkowski F, Chalabi N, Satih S, Bignon YJ, Bernard-Gallon DJ. Central adiposity as a major risk factor of ovarian cancer. Anticancer Res. 2009;29(12):5229-34. PubMed PMID: 20044641.

2. Pavelka JC, Brown RS, Karlan BY, Cass I, Leuchter RS, Lagasse LD, et al. Effect of obesity on survival in epithelial ovarian cancer. Cancer. 2006;107(7):1520-4. PubMed PMID: 16941453.

3. Olsen CM, Green AC, Whiteman DC, Sadeghi S, Kolahdooz F, Webb PM. Obesity and the risk of epithelial ovarian cancer: a systematic review and meta-analysis. Eur J Cancer. 2007;43(4):690-709. PubMed PMID: 17223544.

4. Leitzmann MF, Koebnick C, Danforth KN, Brinton LA, Moore SC, Hollenbeck AR, et al. Body mass index and risk of ovarian cancer. Cancer. 2009;115(4):812-22. PubMed PMID: 19127552.

5. Guh DP, Zhang W, Bansback N, Amarsi Z, Birmingham CL, Anis AH. The incidence of co-morbidities related to obesity and overweight: a systematic review and meta-analysis. BMC Public Health. 2009;9:88. PubMed PMID: 19320986.

6. Lahmann $\mathrm{PH}$, Cust $\mathrm{AE}$, Friedenreich $\mathrm{CM}$, Schulz M, Lukanova A, Kaaks R, et al. Anthropometric measures and epithelial ovarian cancer risk in the European Prospective Investigation into Cancer and Nutrition. Int J Cancer.126(10):2404-15. PubMed PMID: 19821492. 
7. Calle EE, Rodriguez C, Walker-Thurmond K, Thun MJ. Overweight, obesity, and mortality from cancer in a prospectively studied cohort of U.S. adults. The New England journal of medicine. 2003;348(17):1625-38. PubMed PMID: 12711737.

8. Schouten LJ, Goldbohm RA, van den Brandt PA. Height, weight, weight change, and ovarian cancer risk in the Netherlands cohort study on diet and cancer. Am J Epidemiol. 2003;157(5):424-33. Epub 2003/03/05. PubMed PMID: 12615607.

9. Fairfield KM, Willett WC, Rosner BA, Manson JE, Speizer FE, Hankinson SE. Obesity, weight gain, and ovarian cancer. Obstet Gynecol. 2002;100(2):288-96. Epub 2002/08/02. PubMed PMID: 12151152.

10. Chionh F, Baglietto L, Krishnan K, English DR, Maclnnis RJ, Gertig DM, et al. Physical activity, body size and composition, and risk of ovarian cancer. Cancer causes \& control : CCC. 2010;21(12):2183-94. Epub 2010/09/10. doi: 10.1007/s10552-010-9638-y. PubMed PMID: 20827504.

11. Rodriguez C, Calle EE, Fakhrabadi-Shokoohi D, Jacobs EJ, Thun MJ. Body mass index, height, and the risk of ovarian cancer mortality in a prospective cohort of postmenopausal women. Cancer Epidemiol Biomarkers Prev. 2002;11(9):822-8. Epub 2002/09/12. PubMed PMID: 12223425.

12. Lubin F, Chetrit A, Freedman LS, Alfandary E, Fishler $\mathrm{Y}$, Nitzan H, et al. Body mass index at age 18 years and during adult life and ovarian cancer risk. American journal of epidemiology. 2003;157(2):113-20. Epub 2003/01/11. PubMed PMID: 12522018.

13. Engeland A, Tretli S, Bjorge T. Height, body mass index, and ovarian cancer: a follow-up of 1.1 million Norwegian women. J Natl Cancer Inst. 2003;95(16):1244-8. Epub 2003/08/21. PubMed PMID: 12928351.

14. Reeves GK, Pirie K, Beral V, Green J, Spencer E, Bull D. Cancer incidence and mortality in relation to body mass index in the Million Women Study: cohort study. BMJ. 2007;335(7630):1134. Epub 2007/11/08. doi: 10.1136/bmj.39367.495995.AE. PubMed PMID: 17986716; PubMed Central PMCID: PMC2099519.

15. Engeland A, Bjorge T, Selmer RM, Tverdal A. Height and body mass index in relation to total mortality. Epidemiology. 2003;14(3):293-9. Epub 2003/07/16. PubMed PMID: 12859029. 
Supplemental Table 1. Genes Down-regulated when Comparing Ovarian Tumors from Normal Weight $(B M I<25)$ versus Overweight/Obese (BMI $\geq 25$ ) Women.

\begin{tabular}{|c|c|c|c|c|}
\hline Gene Name & David Gene Name & beta & pval & qval \\
\hline TRIM31 & tripartite motif-containing 31 & -4.48216 & $1.18 \mathrm{E}-05$ & 0.010901 \\
\hline ADCY2 & adenylate cyclase 2 (brain) & -4.38132 & $1.81 \mathrm{E}-05$ & 0.012207 \\
\hline NPPC & $\begin{array}{l}\text { natriuretic peptide precursor } \\
\text { C }\end{array}$ & -4.14758 & $4.76 \mathrm{E}-05$ & 0.017198 \\
\hline ST8SIA2 & $\begin{array}{l}\text { ST8 alpha-N-acetyl- } \\
\text { neuraminide alpha-2,8- } \\
\text { sialyltransferase } 2\end{array}$ & -4.10055 & $5.76 \mathrm{E}-05$ & 0.017198 \\
\hline PRRG3 & $\begin{array}{l}\text { proline rich Gla (G- } \\
\text { carboxyglutamic acid) } 3 \\
\text { (transmembrane) }\end{array}$ & -4.04219 & 7.27E-05 & 0.018246 \\
\hline AFF3 & AF4/FMR2 family, member 3 & -4.01323 & $8.16 \mathrm{E}-05$ & 0.019262 \\
\hline LRTM1 & $\begin{array}{l}\text { leucine-rich repeats and } \\
\text { transmembrane domains } 1\end{array}$ & -3.84542 & 0.000157 & 0.024712 \\
\hline NDST3 & $\begin{array}{l}\mathrm{N} \text {-deacetylase/N- } \\
\text { sulfotransferase (heparan } \\
\text { glucosaminyl) } 3\end{array}$ & -3.82115 & 0.000172 & 0.025086 \\
\hline ASCL1 & $\begin{array}{l}\text { achaete-scute complex } \\
\text { homolog } 1 \text { (Drosophila) }\end{array}$ & -3.78407 & 0.000198 & 0.02575 \\
\hline SARDH & sarcosine dehydrogenase & -3.77114 & 0.000208 & 0.025791 \\
\hline DTX3 & $\begin{array}{l}\text { deltex homolog } 3 \\
\text { (Drosophila) }\end{array}$ & -3.7482 & 0.000226 & 0.027 \\
\hline ZNF215 & zinc finger protein 215 & -3.68747 & 0.000284 & 0.030808 \\
\hline KCNK2 & $\begin{array}{l}\text { potassium channel, subfamily } \\
\mathrm{K} \text {, member } 2\end{array}$ & -3.63861 & 0.00034 & 0.034696 \\
\hline IGSF3 & $\begin{array}{l}\text { immunoglobulin superfamily, } \\
\text { member } 3\end{array}$ & -3.63253 & 0.000348 & 0.034748 \\
\hline PRLR & prolactin receptor & -3.62432 & 0.000358 & 0.034851 \\
\hline GRM4 & $\begin{array}{l}\text { glutamate receptor, } \\
\text { metabotropic } 4\end{array}$ & -3.62384 & 0.000359 & 0.034851 \\
\hline REN & renin & -3.61385 & 0.000372 & 0.035074 \\
\hline NPAS1 & $\begin{array}{l}\text { neuronal PAS domain protein } \\
1\end{array}$ & -3.56186 & 0.000449 & 0.038932 \\
\hline LY6G6E & $\begin{array}{l}\text { lymphocyte antigen } 6 \\
\text { complex, locus G6E }\end{array}$ & -3.51691 & 0.000528 & 0.042673 \\
\hline NEBL & nebulette & -3.51145 & 0.000538 & 0.042937 \\
\hline GRIN1 & $\begin{array}{l}\text { glutamate receptor, } \\
\text { ionotropic, N-methyl D- } \\
\text { aspartate } 1\end{array}$ & -3.50008 & 0.000561 & 0.043839 \\
\hline BMP5 & $\begin{array}{l}\text { bone morphogenetic protein } \\
5\end{array}$ & -3.49547 & 0.00057 & 0.043992 \\
\hline ADRA1A & $\begin{array}{l}\text { adrenergic, alpha-1A-, } \\
\text { receptor }\end{array}$ & -3.44328 & 0.000685 & 0.047783 \\
\hline GFI1B & $\begin{array}{l}\text { growth factor independent } 1 \mathrm{~B} \\
\text { transcription repressor }\end{array}$ & -3.41696 & 0.000751 & 0.0514 \\
\hline SLC6A11 & $\begin{array}{l}\text { solute carrier family } 6 \\
\text { (neurotransmitter } \\
\text { transporter, GABA), member }\end{array}$ & -3.4121 & 0.000764 & 0.051702 \\
\hline
\end{tabular}




\begin{tabular}{|c|c|c|c|c|}
\hline & 11 & & & \\
\hline CYP3A43 & $\begin{array}{l}\text { cytochrome P450, family } 3, \\
\text { subfamily A, polypeptide } 43\end{array}$ & -3.39242 & 0.000818 & 0.052859 \\
\hline DTX2 & $\begin{array}{l}\text { deltex homolog } 2 \\
\text { (Drosophila) }\end{array}$ & -3.37829 & 0.000859 & 0.053905 \\
\hline GEMIN7 & $\begin{array}{l}\text { gem (nuclear organelle) } \\
\text { associated protein } 7\end{array}$ & -3.36442 & 0.000902 & 0.055679 \\
\hline DCC & $\begin{array}{l}\text { deleted in colorectal } \\
\text { carcinoma }\end{array}$ & -3.35303 & 0.000938 & 0.05646 \\
\hline TYR & $\begin{array}{l}\text { tyrosinase-like (pseudogene); } \\
\text { tyrosinase (oculocutaneous } \\
\text { albinism IA) }\end{array}$ & -3.34637 & 0.000959 & 0.057278 \\
\hline PCP4 & Purkinje cell protein 4 & -3.32926 & 0.001017 & 0.059746 \\
\hline CLEC10A & $\begin{array}{l}\text { C-type lectin domain family } \\
10, \text { member A }\end{array}$ & -3.2873 & 0.001174 & 0.064009 \\
\hline EDN2 & endothelin 2 & -3.26893 & 0.001249 & 0.066244 \\
\hline LDB3 & LIM domain binding 3 & -3.26435 & 0.001268 & 0.066785 \\
\hline PPY & pancreatic polypeptide & -3.26022 & 0.001286 & 0.066808 \\
\hline LOC90925 & $\begin{array}{l}\text { hypothetical protein } \\
\text { LOC90925 }\end{array}$ & -3.25545 & 0.001307 & 0.066808 \\
\hline DOK4 & docking protein 4 & -3.25482 & 0.001309 & 0.066808 \\
\hline CEMP1 & cementum protein 1 & -3.2488 & 0.001336 & 0.066808 \\
\hline RREB1 & $\begin{array}{l}\text { ras responsive element } \\
\text { binding protein } 1\end{array}$ & -3.22775 & 0.001434 & 0.069063 \\
\hline ATOH1 & $\begin{array}{l}\text { atonal homolog } 1 \\
\text { (Drosophila) }\end{array}$ & -3.21949 & 0.001474 & 0.069874 \\
\hline TNNI1 & $\begin{array}{l}\text { troponin I type } 1 \text { (skeletal, } \\
\text { slow) }\end{array}$ & -3.1982 & 0.001582 & 0.072706 \\
\hline GPR45 & $\begin{array}{l}\text { G protein-coupled receptor } \\
45\end{array}$ & -3.1958 & 0.001595 & 0.073008 \\
\hline ANXA9 & annexin A9 & -3.19128 & 0.001619 & 0.07383 \\
\hline KISS1 & KiSS-1 metastasis-suppressor & -3.18816 & 0.001635 & 0.074314 \\
\hline TSKS & $\begin{array}{l}\text { testis-specific serine kinase } \\
\text { substrate }\end{array}$ & -3.17906 & 0.001685 & 0.075726 \\
\hline KCNQ2 & $\begin{array}{l}\text { potassium voltage-gated } \\
\text { channel, KQT-like subfamily, } \\
\text { member } 2\end{array}$ & -3.1607 & 0.00179 & 0.078683 \\
\hline FL20184 & hypothetical protein FL20184 & -3.15415 & 0.001829 & 0.079906 \\
\hline USH1C & $\begin{array}{l}\text { Usher syndrome 1C } \\
\text { (autosomal recessive, severe) }\end{array}$ & -3.15268 & 0.001838 & 0.079906 \\
\hline TNFRSF10C & $\begin{array}{l}\text { tumor necrosis factor } \\
\text { receptor superfamily, } \\
\text { member } 10 c \text {, decoy without } \\
\text { an intracellular domain }\end{array}$ & -3.14483 & 0.001886 & 0.08082 \\
\hline RBP3 & $\begin{array}{l}\text { retinol binding protein 3, } \\
\text { interstitial }\end{array}$ & -3.13642 & 0.001939 & 0.081536 \\
\hline APOBEC1 & $\begin{array}{l}\text { apolipoprotein B mRNA } \\
\text { editing enzyme, catalytic } \\
\text { polypeptide } 1\end{array}$ & -3.12 & 0.002045 & 0.083414 \\
\hline AKAP6 & $\begin{array}{l}\text { A kinase (PRKA) anchor } \\
\text { protein } 6\end{array}$ & -3.11712 & 0.002064 & 0.083414 \\
\hline
\end{tabular}




\begin{tabular}{|c|c|c|c|c|}
\hline CRYBB1 & crystallin, beta B1 & -3.11167 & 0.002101 & 0.083414 \\
\hline HCN3 & $\begin{array}{l}\text { hyperpolarization activated } \\
\text { cyclic nucleotide-gated } \\
\text { potassium channel } 3\end{array}$ & -3.09871 & 0.002191 & 0.08512 \\
\hline ATP6V1B1 & $\begin{array}{l}\text { ATPase, } \mathrm{H}+\text { transporting, } \\
\text { lysosomal } 56 / 58 \mathrm{kDa}, \mathrm{V} 1 \\
\text { subunit B1 }\end{array}$ & -3.08989 & 0.002255 & 0.086295 \\
\hline A4GNT & $\begin{array}{l}\text { alpha-1,4-N- } \\
\text { acetylglucosaminyltransferas } \\
\text { e }\end{array}$ & -3.08678 & 0.002277 & 0.086295 \\
\hline FNDC8 & $\begin{array}{l}\text { fibronectin type III domain } \\
\text { containing } 8\end{array}$ & -3.08561 & 0.002286 & 0.086295 \\
\hline ATP1B4 & $\begin{array}{l}\text { ATPase, }(\mathrm{Na}+) / \mathrm{K}+ \\
\text { transporting, beta } 4 \\
\text { polypeptide }\end{array}$ & -3.07507 & 0.002365 & 0.088035 \\
\hline PENK & proenkephalin & -3.0679 & 0.00242 & 0.088848 \\
\hline NAP1L4 & $\begin{array}{l}\text { nucleosome assembly protein } \\
\text { 1-like } 4\end{array}$ & -3.06204 & 0.002466 & 0.089228 \\
\hline $\mathrm{CDH} 19$ & cadherin 19, type 2 & -3.04891 & 0.002572 & 0.091356 \\
\hline ACTN3 & actinin, alpha 3 & -3.03098 & 0.002723 & 0.092698 \\
\hline ANG & $\begin{array}{l}\text { angiogenin, ribonuclease, } \\
\text { RNase A family, } 5\end{array}$ & -3.02569 & 0.002769 & 0.093808 \\
\hline PCDHGA3 & $\begin{array}{l}\text { protocadherin gamma } \\
\text { subfamily } A, 3\end{array}$ & -3.02294 & 0.002793 & 0.094227 \\
\hline HRC & $\begin{array}{l}\text { histidine rich calcium binding } \\
\text { protein }\end{array}$ & -3.01732 & 0.002844 & 0.095123 \\
\hline OR5I1 & $\begin{array}{l}\text { olfactory receptor, family 5, } \\
\text { subfamily I, member } 1\end{array}$ & -2.99049 & 0.003095 & 0.097572 \\
\hline PADI4 & $\begin{array}{l}\text { peptidyl arginine deiminase, } \\
\text { type IV }\end{array}$ & -2.98878 & 0.003112 & 0.097607 \\
\hline B3GALT1 & $\begin{array}{l}\text { UDP-Gal:betaGlcNAc beta } \\
\text { 1,3-galactosyltransferase, } \\
\text { polypeptide } 1\end{array}$ & -2.98477 & 0.003151 & 0.097932 \\
\hline
\end{tabular}


Supplemental Table 2. Genes Up-regulated when Comparing Ovarian Tumors from Normal Weight (BMI $<25)$ versus Overweight/Obese $(B M I \geq 25)$ Women.

\begin{tabular}{|c|c|c|c|c|}
\hline Gene Name & David Gene Name & beta & pval & qval \\
\hline ITFG1 & $\begin{array}{l}\text { integrin alpha FG-GAP } \\
\text { repeat containing } 1\end{array}$ & 2.975429 & 0.003245 & 0.098434 \\
\hline ICMT & $\begin{array}{l}\text { isoprenylcysteine } \\
\text { carboxyl } \\
\text { methyltransferase }\end{array}$ & 2.975799 & 0.003241 & 0.098434 \\
\hline SRPR & $\begin{array}{l}\text { signal recognition } \\
\text { particle receptor } \\
\text { (docking protein) }\end{array}$ & 2.976675 & 0.003233 & 0.098434 \\
\hline CXCL13 & $\begin{array}{l}\text { chemokine (C-X-C } \\
\text { motif) ligand } 13\end{array}$ & 2.980288 & 0.003196 & 0.097932 \\
\hline TTC35 & $\begin{array}{l}\text { tetratricopeptide } \\
\text { repeat domain } 35\end{array}$ & 2.980512 & 0.003194 & 0.097932 \\
\hline ERGIC2 & ERGIC and golgi 2 & 2.981139 & 0.003188 & 0.097932 \\
\hline BBS4 & $\begin{array}{l}\text { Bardet-Biedl syndrome } \\
4\end{array}$ & 2.981241 & 0.003187 & 0.097932 \\
\hline MARF5 & $\begin{array}{l}\text { membrane-associated } \\
\text { ring finger (C3HC4) } 5\end{array}$ & 2.981251 & 0.003186 & 0.097932 \\
\hline MS4A4A & $\begin{array}{l}\text { membrane-spanning } \\
\text { 4-domains, subfamily } \\
\text { A, member } 4\end{array}$ & 2.982922 & 0.00317 & 0.097932 \\
\hline NFIL3 & $\begin{array}{l}\text { nuclear factor, } \\
\text { interleukin } 3 \text { regulated }\end{array}$ & 2.985834 & 0.003141 & 0.097932 \\
\hline BCAS2 & $\begin{array}{l}\text { breast carcinoma } \\
\text { amplified sequence } 2\end{array}$ & 2.988719 & 0.003113 & 0.097607 \\
\hline BIN2 & bridging integrator 2 & 2.991432 & 0.003086 & 0.097539 \\
\hline HLA-DMA & $\begin{array}{l}\text { major } \\
\text { histocompatibility } \\
\text { complex, class II, DM } \\
\text { alpha }\end{array}$ & 2.99241 & 0.003077 & 0.097495 \\
\hline STX12 & syntaxin 12 & 2.992448 & 0.003076 & 0.097495 \\
\hline MPHOSPH9 & $\begin{array}{l}\text { M-phase } \\
\text { phosphoprotein } 9\end{array}$ & 2.993968 & 0.003062 & 0.097495 \\
\hline POSTN & $\begin{array}{l}\text { periostin, osteoblast } \\
\text { specific factor }\end{array}$ & 2.994647 & 0.003055 & 0.097495 \\
\hline DYRK3 & $\begin{array}{l}\text { dual-specificity } \\
\text { tyrosine-(Y)- } \\
\text { phosphorylation } \\
\text { regulated kinase } 3\end{array}$ & 2.994974 & 0.003052 & 0.097495 \\
\hline NME6 & $\begin{array}{l}\text { non-metastatic cells 6, } \\
\text { protein expressed in } \\
\text { (nucleoside- } \\
\text { diphosphate kinase) }\end{array}$ & 2.995291 & 0.003049 & 0.097495 \\
\hline COPS3 & $\begin{array}{l}\text { COP9 constitutive } \\
\text { photomorphogenic } \\
\text { homolog subunit } 3 \\
\text { (Arabidopsis) }\end{array}$ & 2.997299 & 0.00303 & 0.097495 \\
\hline SNX13 & sorting nexin 13 & 2.999238 & 0.003011 & 0.09721 \\
\hline
\end{tabular}




\begin{tabular}{|c|c|c|c|c|}
\hline TUSC2 & $\begin{array}{l}\text { tumor suppressor } \\
\text { candidate } 2\end{array}$ & 3.002712 & 0.002978 & 0.096668 \\
\hline RGS5 & $\begin{array}{l}\text { regulator of G-protein } \\
\text { signaling } 5\end{array}$ & 3.002867 & 0.002977 & 0.096668 \\
\hline ZMAT3 & $\begin{array}{l}\text { zinc finger, matrin type } \\
3\end{array}$ & 3.003224 & 0.002973 & 0.096668 \\
\hline HLA-DRB1 & $\begin{array}{l}\text { major } \\
\text { histocompatibility } \\
\text { complex, class II, DR } \\
\text { beta 4; major } \\
\text { histocompatibility } \\
\text { complex, class II, DR } \\
\text { beta 1 }\end{array}$ & 3.005869 & 0.002949 & 0.096668 \\
\hline CUL2 & cullin 2 & 3.008667 & 0.002923 & 0.096198 \\
\hline CTSS & cathepsin S & 3.011933 & 0.002893 & 0.09596 \\
\hline UMPS & $\begin{array}{l}\text { uridine } \\
\text { monophosphate } \\
\text { synthetase }\end{array}$ & 3.014414 & 0.00287 & 0.095578 \\
\hline FAHD2A & $\begin{array}{l}\text { fumarylacetoacetate } \\
\text { hydrolase domain } \\
\text { containing } 2 \mathrm{~A}\end{array}$ & 3.017367 & 0.002843 & 0.095123 \\
\hline SAMM50 & $\begin{array}{l}\text { sorting and assembly } \\
\text { machinery component } \\
50 \text { homolog (S. } \\
\text { cerevisiae) }\end{array}$ & 3.034131 & 0.002696 & 0.092227 \\
\hline PSMB9 & $\begin{array}{l}\text { proteasome (prosome, } \\
\text { macropain) subunit, } \\
\text { beta type, } 9 \text { (large } \\
\text { multifunctional } \\
\text { peptidase } 2 \text { ) }\end{array}$ & 3.034322 & 0.002694 & 0.092227 \\
\hline CHEK2 & $\begin{array}{l}\text { protein kinase CHK2- } \\
\text { like; CHK2 checkpoint } \\
\text { homolog (S. pombe); } \\
\text { similar to hCG1983233 }\end{array}$ & 3.034329 & 0.002694 & 0.092227 \\
\hline ZBTB5 & $\begin{array}{l}\text { zinc finger and BTB } \\
\text { domain containing } 5\end{array}$ & 3.038413 & 0.002659 & 0.092227 \\
\hline PBLD & $\begin{array}{l}\text { phenazine } \\
\text { biosynthesis-like } \\
\text { protein domain } \\
\text { containing }\end{array}$ & 3.038583 & 0.002658 & 0.092227 \\
\hline DAB2 & $\begin{array}{l}\text { disabled homolog 2, } \\
\text { mitogen-responsive } \\
\text { phosphoprotein } \\
\text { (Drosophila) }\end{array}$ & 3.039081 & 0.002654 & 0.092227 \\
\hline ISOC1 & $\begin{array}{l}\text { isochorismatase } \\
\text { domain containing } 1\end{array}$ & 3.040811 & 0.002639 & 0.092227 \\
\hline ANAPC1 & $\begin{array}{l}\text { anaphase promoting } \\
\text { complex subunit } 1 ; \\
\text { similar to anaphase } \\
\text { promoting complex } \\
\text { subunit } 1\end{array}$ & 3.041419 & 0.002634 & 0.092227 \\
\hline GIMAP6 & GTPase, IMAP family & 3.044913 & 0.002605 & 0.091986 \\
\hline
\end{tabular}




\begin{tabular}{|c|c|c|c|c|}
\hline & member 6 & & & \\
\hline MT1X & metallothionein $1 \mathrm{X}$ & 3.046247 & 0.002594 & 0.091865 \\
\hline LY86 & lymphocyte antigen 86 & 3.05035 & 0.00256 & 0.091205 \\
\hline HEG1 & $\begin{array}{l}\text { HEG homolog } 1 \\
\text { (zebrafish) }\end{array}$ & 3.055065 & 0.002522 & 0.090487 \\
\hline CTPS & CTP synthase & 3.055809 & 0.002516 & 0.090487 \\
\hline SDCCAG3 & $\begin{array}{l}\text { serologically defined } \\
\text { colon cancer antigen 3; } \\
\text { similar to Serologically } \\
\text { defined colon cancer } \\
\text { antigen } 3\end{array}$ & 3.061854 & 0.002467 & 0.089228 \\
\hline RARRES1 & $\begin{array}{l}\text { retinoic acid receptor } \\
\text { responder (tazarotene } \\
\text { induced) } 1\end{array}$ & 3.062645 & 0.002461 & 0.089228 \\
\hline TGFBR2 & $\begin{array}{l}\text { transforming growth } \\
\text { factor, beta receptor II } \\
(70 / 80 \mathrm{kDa})\end{array}$ & 3.064944 & 0.002443 & 0.089151 \\
\hline SEC16A & $\begin{array}{l}\text { SEC16 homolog A (S. } \\
\text { cerevisiae) }\end{array}$ & 3.06624 & 0.002433 & 0.089051 \\
\hline TXN2 & thioredoxin 2 & 3.072266 & 0.002386 & 0.08842 \\
\hline MS4A6A & $\begin{array}{l}\text { membrane-spanning } \\
\text { 4-domains, subfamily } \\
\text { A, member } 6 \mathrm{~A}\end{array}$ & 3.07458 & 0.002369 & 0.088035 \\
\hline IFI35 & $\begin{array}{l}\text { interferon-induced } \\
\text { protein } 35\end{array}$ & 3.076162 & 0.002357 & 0.088035 \\
\hline RAP1A & $\begin{array}{l}\text { RAP1A, member of } \\
\text { RAS oncogene family }\end{array}$ & 3.07827 & 0.002341 & 0.087809 \\
\hline TBC1D15 & $\begin{array}{l}\text { TBC1 domain family, } \\
\text { member } 15\end{array}$ & 3.085759 & 0.002285 & 0.086295 \\
\hline WDR8 & WD repeat domain 8 & 3.086918 & 0.002276 & 0.086295 \\
\hline GCC2 & $\begin{array}{l}\text { GRIP and coiled-coil } \\
\text { domain containing } 2\end{array}$ & 3.087191 & 0.002274 & 0.086295 \\
\hline ADK & adenosine kinase & 3.091248 & 0.002245 & 0.086295 \\
\hline TWF2 & $\begin{array}{l}\text { twinfilin, actin-binding } \\
\text { protein, homolog } 2 \\
\text { (Drosophila) }\end{array}$ & 3.093722 & 0.002227 & 0.086227 \\
\hline SNRPD3 & $\begin{array}{l}\text { small nuclear } \\
\text { ribonucleoprotein D3 } \\
\text { polypeptide } 18 \mathrm{kDa}\end{array}$ & 3.102406 & 0.002165 & 0.084655 \\
\hline SELL & selectin L & 3.103068 & 0.002161 & 0.084655 \\
\hline USP15 & $\begin{array}{l}\text { ubiquitin specific } \\
\text { peptidase } 15\end{array}$ & 3.106605 & 0.002136 & 0.084057 \\
\hline SNAP29 & $\begin{array}{l}\text { synaptosomal- } \\
\text { associated protein, } \\
29 \mathrm{kDa}\end{array}$ & 3.110996 & 0.002106 & 0.083414 \\
\hline COPZ2 & $\begin{array}{l}\text { coatomer protein } \\
\text { complex, subunit zeta } \\
2\end{array}$ & 3.111006 & 0.002106 & 0.083414 \\
\hline GABARAPL2 & $\begin{array}{l}\text { GABA }(A) \text { receptor- } \\
\text { associated protein-like } \\
2\end{array}$ & 3.111733 & 0.002101 & 0.083414 \\
\hline GBA & glucosidase, beta; acid & 3.111935 & 0.002099 & 0.083414 \\
\hline
\end{tabular}




\begin{tabular}{|c|c|c|c|c|}
\hline & $\begin{array}{l}\text { (includes } \\
\text { glucosylceramidase) }\end{array}$ & & & \\
\hline KDELR2 & $\begin{array}{l}\text { KDEL (Lys-Asp-Glu-Leu) } \\
\text { endoplasmic reticulum } \\
\text { protein retention } \\
\text { receptor } 2\end{array}$ & 3.113233 & 0.002091 & 0.083414 \\
\hline PLAUR & $\begin{array}{l}\text { plasminogen activator, } \\
\text { urokinase receptor }\end{array}$ & 3.113244 & 0.00209 & 0.083414 \\
\hline WDR61 & WD repeat domain 61 & 3.115266 & 0.002077 & 0.083414 \\
\hline ZC3H7A & $\begin{array}{l}\text { zinc finger } \mathrm{CCCH} \text {-type } \\
\text { containing } 7 \mathrm{~A}\end{array}$ & 3.116933 & 0.002066 & 0.083414 \\
\hline CLINT1 & clathrin interactor 1 & 3.118625 & 0.002054 & 0.083414 \\
\hline PPP2R3C & $\begin{array}{l}\text { protein phosphatase } 2 \\
\text { (formerly } 2 A \text { ), } \\
\text { regulatory subunit B", } \\
\text { gamma }\end{array}$ & 3.119822 & 0.002046 & 0.083414 \\
\hline KIF2A & $\begin{array}{l}\text { kinesin heavy chain } \\
\text { member } 2 \mathrm{~A}\end{array}$ & 3.13211 & 0.001966 & 0.08162 \\
\hline WDR5B & WD repeat domain $5 \mathrm{~B}$ & 3.133142 & 0.001959 & 0.08162 \\
\hline CD46 & $\begin{array}{l}\text { CD46 molecule, } \\
\text { complement } \\
\text { regulatory protein }\end{array}$ & 3.133857 & 0.001955 & 0.08162 \\
\hline $\mathrm{CCNH}$ & cyclin $\mathrm{H}$ & 3.135669 & 0.001943 & 0.081536 \\
\hline MPHOSPH6 & $\begin{array}{l}\text { M-phase } \\
\text { phosphoprotein } 6\end{array}$ & 3.136632 & 0.001937 & 0.081536 \\
\hline SRGN & serglycin & 3.137016 & 0.001935 & 0.081536 \\
\hline FCER1G & $\begin{array}{l}\text { Fc fragment of IgE, } \\
\text { high affinity I, receptor } \\
\text { for; gamma } \\
\text { polypeptide }\end{array}$ & 3.139755 & 0.001918 & 0.081536 \\
\hline PDIA6 & $\begin{array}{l}\text { protein disulfide } \\
\text { isomerase family A, } \\
\text { member } 6\end{array}$ & 3.143351 & 0.001895 & 0.080925 \\
\hline SLC25A44 & $\begin{array}{l}\text { solute carrier family } \\
25, \text { member } 44\end{array}$ & 3.145965 & 0.001879 & 0.080809 \\
\hline TTC4 & $\begin{array}{l}\text { tetratricopeptide } \\
\text { repeat domain } 4\end{array}$ & 3.146457 & 0.001876 & 0.080809 \\
\hline QRICH1 & glutamine-rich 1 & 3.149489 & 0.001857 & 0.080456 \\
\hline SPSB1 & $\begin{array}{l}\text { splA/ryanodine } \\
\text { receptor domain and } \\
\text { SOCS box containing } 1\end{array}$ & 3.153107 & 0.001835 & 0.079906 \\
\hline C3AR1 & $\begin{array}{l}\text { complement } \\
\text { component 3a } \\
\text { receptor } 1\end{array}$ & 3.161055 & 0.001788 & 0.078683 \\
\hline MMACHC & $\begin{array}{l}\text { methylmalonic } \\
\text { aciduria (cobalamin } \\
\text { deficiency) cblC type, } \\
\text { with homocystinuria }\end{array}$ & 3.163894 & 0.001772 & 0.078433 \\
\hline IL13RA1 & $\begin{array}{l}\text { interleukin } 13 \\
\text { receptor, alpha } 1\end{array}$ & 3.169883 & 0.001737 & 0.077473 \\
\hline GIMAP5 & $\begin{array}{l}\text { GTPase, IMAP family } \\
\text { member } 5\end{array}$ & 3.175218 & 0.001707 & 0.076406 \\
\hline
\end{tabular}




\begin{tabular}{|c|c|c|c|c|}
\hline PLK3 & $\begin{array}{l}\text { polo-like kinase } 3 \\
\text { (Drosophila) }\end{array}$ & 3.18564 & 0.001649 & 0.074654 \\
\hline SCAMP3 & $\begin{array}{l}\text { secretory carrier } \\
\text { membrane protein } 3\end{array}$ & 3.201424 & 0.001565 & 0.07221 \\
\hline CoL1A1 & $\begin{array}{l}\text { collagen, type I, alpha } \\
1\end{array}$ & 3.206061 & 0.001541 & 0.071656 \\
\hline PELO & $\begin{array}{l}\text { pelota homolog } \\
\text { (Drosophila) }\end{array}$ & 3.207003 & 0.001536 & 0.071656 \\
\hline TMEM186 & $\begin{array}{l}\text { transmembrane } \\
\text { protein } 186\end{array}$ & 3.216482 & 0.001489 & 0.070026 \\
\hline LYZ & $\begin{array}{l}\text { lysozyme (renal } \\
\text { amyloidosis) }\end{array}$ & 3.216871 & 0.001487 & 0.070026 \\
\hline ZW10 & $\begin{array}{l}\text { ZW10, kinetochore } \\
\text { associated, homolog } \\
\text { (Drosophila) }\end{array}$ & 3.221216 & 0.001465 & 0.069747 \\
\hline RRAGC & $\begin{array}{l}\text { Ras-related GTP } \\
\text { binding C }\end{array}$ & 3.2252 & 0.001446 & 0.0691 \\
\hline TNFAIP6 & $\begin{array}{l}\text { tumor necrosis factor, } \\
\text { alpha-induced protein } \\
6\end{array}$ & 3.225375 & 0.001445 & 0.0691 \\
\hline TMEM140 & $\begin{array}{l}\text { transmembrane } \\
\text { protein } 140\end{array}$ & 3.232927 & 0.001409 & 0.068236 \\
\hline COQ10B & $\begin{array}{l}\text { coenzyme Q10 } \\
\text { homolog B (S. } \\
\text { cerevisiae) }\end{array}$ & 3.236808 & 0.001391 & 0.067816 \\
\hline SLC26A6 & $\begin{array}{l}\text { solute carrier family } \\
\text { 26, member 6; } \\
\text { cadherin, EGF LAG } \\
\text { seven-pass G-type } \\
\text { receptor } 3 \text { (flamingo } \\
\text { homolog, Drosophila) }\end{array}$ & 3.239502 & 0.001379 & 0.06748 \\
\hline TLR2 & toll-like receptor 2 & 3.24267 & 0.001364 & 0.067041 \\
\hline ATG4A & $\begin{array}{l}\text { ATG4 autophagy } \\
\text { related } 4 \text { homolog A } \\
\text { (S. cerevisiae) }\end{array}$ & 3.243065 & 0.001362 & 0.067041 \\
\hline COL5A1 & $\begin{array}{l}\text { collagen, type } V \text {, alpha } \\
1\end{array}$ & 3.243879 & 0.001358 & 0.067041 \\
\hline INTS12 & $\begin{array}{l}\text { integrator complex } \\
\text { subunit } 12\end{array}$ & 3.244605 & 0.001355 & 0.067041 \\
\hline SLC25A20 & $\begin{array}{l}\text { solute carrier family } 25 \\
\text { (carnitine/acylcarnitine } \\
\text { translocase), member } \\
20\end{array}$ & 3.248614 & 0.001337 & 0.066808 \\
\hline ALAS1 & $\begin{array}{l}\text { aminolevulinate, delta- } \\
\text {, synthase } 1\end{array}$ & 3.251697 & 0.001323 & 0.066808 \\
\hline DALRD3 & $\begin{array}{l}\text { DALR anticodon } \\
\text { binding domain } \\
\text { containing } 3\end{array}$ & 3.25221 & 0.001321 & 0.066808 \\
\hline ARHGDIB & $\begin{array}{l}\text { Rho GDP dissociation } \\
\text { inhibitor (GDI) beta }\end{array}$ & 3.253291 & 0.001316 & 0.066808 \\
\hline SNX10 & sorting nexin 10 & 3.255754 & 0.001305 & 0.066808 \\
\hline MAPK1 & mitogen-activated & 3.256458 & 0.001302 & 0.066808 \\
\hline
\end{tabular}




\begin{tabular}{|c|c|c|c|c|}
\hline & protein kinase 1 & & & \\
\hline CYB5R4 & $\begin{array}{l}\text { cytochrome b5 } \\
\text { reductase } 4\end{array}$ & 3.259847 & 0.001288 & 0.066808 \\
\hline RAB7A & $\begin{array}{l}\text { RAB7A, member RAS } \\
\text { oncogene family }\end{array}$ & 3.26971 & 0.001245 & 0.066244 \\
\hline KARS & lysyl-tRNA synthetase & 3.273871 & 0.001228 & 0.065727 \\
\hline LRRC14 & $\begin{array}{l}\text { leucine rich repeat } \\
\text { containing } 14\end{array}$ & 3.279587 & 0.001205 & 0.064757 \\
\hline GZMA & $\begin{array}{l}\text { granzyme A (granzyme } \\
1 \text {, cytotoxic T- } \\
\text { lymphocyte-associated } \\
\text { serine esterase } 3 \text { ) }\end{array}$ & 3.284155 & 0.001186 & 0.06405 \\
\hline PLSCR1 & $\begin{array}{l}\text { phospholipid } \\
\text { scramblase } 1\end{array}$ & 3.284538 & 0.001185 & 0.06405 \\
\hline UBAP1 & $\begin{array}{l}\text { ubiquitin associated } \\
\text { protein } 1\end{array}$ & 3.287006 & 0.001175 & 0.064009 \\
\hline TOMM22 & $\begin{array}{l}\text { translocase of outer } \\
\text { mitochondrial } \\
\text { membrane } 22 \\
\text { homolog (yeast) }\end{array}$ & 3.293449 & 0.001149 & 0.063198 \\
\hline CCDC109B & $\begin{array}{l}\text { coiled-coil domain } \\
\text { containing 109B }\end{array}$ & 3.29933 & 0.001127 & 0.06264 \\
\hline OSTM1 & $\begin{array}{l}\text { osteopetrosis } \\
\text { associated } \\
\text { transmembrane } \\
\text { protein } 1\end{array}$ & 3.301385 & 0.001119 & 0.06264 \\
\hline PPIE & $\begin{array}{l}\text { peptidylprolyl } \\
\text { isomerase E } \\
\text { (cyclophilin E) }\end{array}$ & 3.304849 & 0.001106 & 0.062219 \\
\hline AZI2 & $\begin{array}{l}\text { 5-azacytidine induced } \\
2\end{array}$ & 3.30582 & 0.001102 & 0.062219 \\
\hline MCAM & $\begin{array}{l}\text { melanoma cell } \\
\text { adhesion molecule }\end{array}$ & 3.311459 & 0.001081 & 0.061409 \\
\hline IFRD2 & $\begin{array}{l}\text { interferon-related } \\
\text { developmental } \\
\text { regulator } 2\end{array}$ & 3.315881 & 0.001065 & 0.060847 \\
\hline LXN & latexin & 3.317669 & 0.001058 & 0.060847 \\
\hline FBXO38 & F-box protein 38 & 3.32478 & 0.001033 & 0.059809 \\
\hline FLAD1 & $\begin{array}{l}\text { FAD1 flavin adenine } \\
\text { dinucleotide } \\
\text { synthetase homolog } \\
\text { (S. cerevisiae) }\end{array}$ & 3.32523 & 0.001031 & 0.059809 \\
\hline MBD4 & $\begin{array}{l}\text { methyl-CpG binding } \\
\text { domain protein } 4\end{array}$ & 3.327913 & 0.001022 & 0.059746 \\
\hline WDR70 & WD repeat domain 70 & 3.337961 & 0.000988 & 0.058292 \\
\hline SLC33A1 & $\begin{array}{l}\text { solute carrier family } 33 \\
\text { (acetyl-CoA } \\
\text { transporter), member } \\
1\end{array}$ & 3.342665 & 0.000972 & 0.057642 \\
\hline CDR2 & $\begin{array}{l}\text { cerebellar } \\
\text { degeneration-related } \\
\text { protein } 2,62 \mathrm{kDa}\end{array}$ & 3.345947 & 0.000961 & 0.057278 \\
\hline
\end{tabular}




\begin{tabular}{|c|c|c|c|c|}
\hline STAT1 & $\begin{array}{l}\text { signal transducer and } \\
\text { activator of } \\
\text { transcription } 1,91 \mathrm{kDa}\end{array}$ & 3.35824 & 0.000921 & 0.055764 \\
\hline NAGK & $\begin{array}{l}\mathrm{N} \text {-acetylglucosamine } \\
\text { kinase }\end{array}$ & 3.359838 & 0.000916 & 0.055764 \\
\hline EBNA1BP2 & $\begin{array}{l}\text { EBNA1 binding protein } \\
2\end{array}$ & 3.361808 & 0.00091 & 0.055764 \\
\hline TOMM70A & $\begin{array}{l}\text { translocase of outer } \\
\text { mitochondrial } \\
\text { membrane } 70 \\
\text { homolog A (S. } \\
\text { cerevisiae) }\end{array}$ & 3.364772 & 0.000901 & 0.055679 \\
\hline $\mathrm{SH} 2 \mathrm{~B} 3$ & $\begin{array}{l}\text { SH2B adaptor protein } \\
3\end{array}$ & 3.375746 & 0.000867 & 0.054099 \\
\hline CORO1A & $\begin{array}{l}\text { coronin, actin binding } \\
\text { protein, } 1 \mathrm{~A}\end{array}$ & 3.382152 & 0.000848 & 0.053467 \\
\hline BECN1 & $\begin{array}{l}\text { beclin 1, autophagy } \\
\text { related }\end{array}$ & 3.390021 & 0.000825 & 0.052859 \\
\hline GAS2L1 & $\begin{array}{l}\text { growth arrest-specific } \\
2 \text { like } 1\end{array}$ & 3.396433 & 0.000807 & 0.052534 \\
\hline AURKAIP1 & $\begin{array}{l}\text { aurora kinase } \mathrm{A} \\
\text { interacting protein } 1\end{array}$ & 3.398482 & 0.000801 & 0.052444 \\
\hline SDF4 & $\begin{array}{l}\text { stromal cell derived } \\
\text { factor } 4\end{array}$ & 3.40093 & 0.000795 & 0.052284 \\
\hline HEMK1 & $\begin{array}{l}\text { HemK } \\
\text { methyltransferase } \\
\text { family member } 1 \\
\end{array}$ & 3.403689 & 0.000787 & 0.052284 \\
\hline THOC5 & THO complex 5 & 3.406858 & 0.000778 & 0.05207 \\
\hline LPXN & leupaxin & 3.410427 & 0.000769 & 0.051714 \\
\hline FASTKD3 & FAST kinase domains 3 & 3.415398 & 0.000756 & 0.0514 \\
\hline YTHDF2 & $\begin{array}{l}\text { YTH domain family, } \\
\text { member } 2\end{array}$ & 3.430981 & 0.000715 & 0.049514 \\
\hline SF3A1 & $\begin{array}{l}\text { splicing factor } 3 a \text {, } \\
\text { subunit } 1,120 \mathrm{kDa}\end{array}$ & 3.442775 & 0.000686 & 0.047783 \\
\hline FAP & $\begin{array}{l}\text { fibroblast activation } \\
\text { protein, alpha }\end{array}$ & 3.446076 & 0.000679 & 0.047783 \\
\hline TMEM110 & $\begin{array}{l}\text { transmembrane } \\
\text { protein 110; } \\
\text { musculoskeletal, } \\
\text { embryonic nuclear } \\
\text { protein } 1\end{array}$ & 3.446145 & 0.000678 & 0.047783 \\
\hline LAIR1 & $\begin{array}{l}\text { leukocyte-associated } \\
\text { immunoglobulin-like } \\
\text { receptor } 1\end{array}$ & 3.451402 & 0.000666 & 0.04763 \\
\hline SDS & serine dehydratase & 3.459563 & 0.000647 & 0.046943 \\
\hline ZBTB40 & $\begin{array}{l}\text { zinc finger and BTB } \\
\text { domain containing } 40\end{array}$ & 3.464996 & 0.000635 & 0.046331 \\
\hline TMEM165 & $\begin{array}{l}\text { transmembrane } \\
\text { protein } 165\end{array}$ & 3.481659 & 0.000599 & 0.044217 \\
\hline ATP6V1C1 & $\begin{array}{l}\text { ATPase, } \mathrm{H}+ \\
\text { transporting, } \\
\text { lysosomal 42kDa, V1 }\end{array}$ & 3.482951 & 0.000596 & 0.044217 \\
\hline
\end{tabular}




\begin{tabular}{|c|c|c|c|c|}
\hline & subunit C1 & & & \\
\hline NR3C1 & $\begin{array}{l}\text { nuclear receptor } \\
\text { subfamily } 3 \text {, group C, } \\
\text { member } 1 \\
\text { (glucocorticoid } \\
\text { receptor) }\end{array}$ & 3.487975 & 0.000585 & 0.044049 \\
\hline ATP6V0B & $\begin{array}{l}\text { ATPase, } \mathrm{H}+ \\
\text { transporting, } \\
\text { lysosomal } 21 \mathrm{kDa}, \mathrm{V} 0 \\
\text { subunit b }\end{array}$ & 3.489342 & 0.000582 & 0.044049 \\
\hline NADK & NAD kinase & 3.4899 & 0.000581 & 0.044049 \\
\hline MACF1 & $\begin{array}{l}\text { microtubule-actin } \\
\text { crosslinking factor } 1\end{array}$ & 3.490847 & 0.000579 & 0.044049 \\
\hline TRIM22 & $\begin{array}{l}\text { tripartite motif- } \\
\text { containing } 22\end{array}$ & 3.496602 & 0.000568 & 0.043992 \\
\hline $\mathrm{B} 2 \mathrm{M}$ & beta-2-microglobulin & 3.504998 & 0.000551 & 0.04336 \\
\hline GPR65 & $\begin{array}{l}\text { G protein-coupled } \\
\text { receptor } 65\end{array}$ & 3.505009 & 0.000551 & 0.04336 \\
\hline RAB5C & $\begin{array}{l}\text { RAB5C, member RAS } \\
\text { oncogene family }\end{array}$ & 3.513949 & 0.000534 & 0.042839 \\
\hline CCL4 & $\begin{array}{l}\text { chemokine (C-C motif) } \\
\text { ligand } 4\end{array}$ & 3.520718 & 0.000521 & 0.042381 \\
\hline ATP6V1A & $\begin{array}{l}\text { ATPase, } \mathrm{H}+ \\
\text { transporting, } \\
\text { lysosomal 70kDa, V1 } \\
\text { subunit A }\end{array}$ & 3.52506 & 0.000513 & 0.042012 \\
\hline SEC22A & $\begin{array}{l}\text { SEC22 vesicle } \\
\text { trafficking protein } \\
\text { homolog A ( } \mathrm{S} \text {. } \\
\text { cerevisiae) }\end{array}$ & 3.525591 & 0.000512 & 0.042012 \\
\hline VGLL3 & $\begin{array}{l}\text { vestigial like } 3 \\
\text { (Drosophila) }\end{array}$ & 3.5275 & 0.000508 & 0.042012 \\
\hline TFRC & $\begin{array}{l}\text { transferrin receptor } \\
(p 90, C D 71)\end{array}$ & 3.533232 & 0.000498 & 0.041651 \\
\hline ATP6V0D1 & $\begin{array}{l}\text { ATPase, } \mathrm{H}+ \\
\text { transporting, } \\
\text { lysosomal } 38 \mathrm{kDa}, \mathrm{V0} \\
\text { subunit d1 }\end{array}$ & 3.540388 & 0.000485 & 0.04088 \\
\hline TFEC & transcription factor EC & 3.547581 & 0.000473 & 0.040119 \\
\hline SLC35E1 & $\begin{array}{l}\text { solute carrier family } \\
35, \text { member E1 }\end{array}$ & 3.554921 & 0.000461 & 0.03935 \\
\hline SAMHD1 & $\begin{array}{l}\text { SAM domain and HD } \\
\text { domain } 1\end{array}$ & 3.555376 & 0.00046 & 0.03935 \\
\hline CTSK & cathepsin K & 3.561861 & 0.000449 & 0.038932 \\
\hline SLA & Src-like-adaptor & 3.573332 & 0.000431 & 0.037898 \\
\hline HLA-DRA & $\begin{array}{l}\text { major } \\
\text { histocompatibility } \\
\text { complex, class II, DR } \\
\text { alpha }\end{array}$ & 3.57644 & 0.000426 & 0.03775 \\
\hline VCAN & versican & 3.579722 & 0.000421 & 0.03758 \\
\hline RHOA & $\begin{array}{l}\text { ras homolog gene } \\
\text { family, member A }\end{array}$ & 3.58531 & 0.000413 & 0.037381 \\
\hline
\end{tabular}




\begin{tabular}{|c|c|c|c|c|}
\hline RAB5A & $\begin{array}{l}\text { RAB5A, member RAS } \\
\text { oncogene family }\end{array}$ & 3.602813 & 0.000387 & 0.03589 \\
\hline LAPTM5 & $\begin{array}{l}\text { lysosomal } \\
\text { multispanning } \\
\text { membrane protein } 5\end{array}$ & 3.605426 & 0.000384 & 0.035826 \\
\hline DPYD & $\begin{array}{l}\text { dihydropyrimidine } \\
\text { dehydrogenase }\end{array}$ & 3.613384 & 0.000373 & 0.035074 \\
\hline IL10RA & $\begin{array}{l}\text { interleukin } 10 \\
\text { receptor, alpha }\end{array}$ & 3.620434 & 0.000363 & 0.035004 \\
\hline RNF14 & ring finger protein 14 & 3.626553 & 0.000355 & 0.034851 \\
\hline ARHGEF6 & $\begin{array}{l}\text { Rac/Cdc42 guanine } \\
\text { nucleotide exchange } \\
\text { factor (GEF) } 6\end{array}$ & 3.631343 & 0.000349 & 0.034748 \\
\hline GMFG & $\begin{array}{l}\text { glia maturation factor, } \\
\text { gamma }\end{array}$ & 3.634541 & 0.000345 & 0.034748 \\
\hline SOAT1 & $\begin{array}{l}\text { sterol O- } \\
\text { acyltransferase } 1\end{array}$ & 3.638757 & 0.00034 & 0.034696 \\
\hline HUS1 & $\begin{array}{l}\text { HUS1 checkpoint } \\
\text { homolog (S. pombe) }\end{array}$ & 3.641383 & 0.000337 & 0.034696 \\
\hline IL2RB & $\begin{array}{l}\text { interleukin } 2 \text { receptor, } \\
\text { beta }\end{array}$ & 3.658249 & 0.000316 & 0.033414 \\
\hline FARS2 & $\begin{array}{l}\text { phenylalanyl-tRNA } \\
\text { synthetase 2, } \\
\text { mitochondrial }\end{array}$ & 3.669773 & 0.000303 & 0.032308 \\
\hline NDUFB3 & $\begin{array}{l}\text { NADH dehydrogenase } \\
\text { (ubiquinone) } 1 \text { beta } \\
\text { subcomplex, } 3,12 \mathrm{kDa}\end{array}$ & 3.677487 & 0.000295 & 0.031681 \\
\hline LRP8 & $\begin{array}{l}\text { low density lipoprotein } \\
\text { receptor-related } \\
\text { protein } 8 \text {, } \\
\text { apolipoprotein e } \\
\text { receptor }\end{array}$ & 3.688705 & 0.000283 & 0.030808 \\
\hline APOL3 & apolipoprotein L, 3 & 3.698826 & 0.000272 & 0.030079 \\
\hline APEH & $\begin{array}{l}\mathrm{N} \text {-acylaminoacyl- } \\
\text { peptide hydrolase }\end{array}$ & 3.700758 & 0.00027 & 0.030079 \\
\hline CD74 & $\begin{array}{l}\text { CD74 molecule, major } \\
\text { histocompatibility } \\
\text { complex, class II } \\
\text { invariant chain }\end{array}$ & 3.70804 & 0.000263 & 0.02961 \\
\hline MFSD1 & $\begin{array}{l}\text { major facilitator } \\
\text { superfamily domain } \\
\text { containing } 1\end{array}$ & 3.709437 & 0.000262 & 0.02961 \\
\hline ABHD5 & $\begin{array}{l}\text { abhydrolase domain } \\
\text { containing } 5\end{array}$ & 3.71473 & 0.000257 & 0.029432 \\
\hline HLA-DPB1 & $\begin{array}{l}\text { major } \\
\text { histocompatibility } \\
\text { complex, class II, DP } \\
\text { beta } 1\end{array}$ & 3.718543 & 0.000253 & 0.029296 \\
\hline ELTD1 & $\begin{array}{l}\text { EGF, latrophilin and } \\
\text { seven transmembrane } \\
\text { domain containing } 1\end{array}$ & 3.740251 & 0.000233 & 0.027544 \\
\hline HERPUD1 & homocysteine- & 3.750708 & 0.000224 & 0.027 \\
\hline
\end{tabular}




\begin{tabular}{|c|c|c|c|c|}
\hline & $\begin{array}{l}\text { inducible, endoplasmic } \\
\text { reticulum stress- } \\
\text { inducible, ubiquitin- } \\
\text { like domain member } 1\end{array}$ & & & \\
\hline NEK4 & $\begin{array}{l}\text { NIMA (never in mitosis } \\
\text { gene a)-related kinase } \\
4\end{array}$ & 3.752824 & 0.000223 & 0.027 \\
\hline APOL1 & apolipoprotein $\mathrm{L}, 1$ & 3.75321 & 0.000222 & 0.027 \\
\hline GTF2E1 & $\begin{array}{l}\text { general transcription } \\
\text { factor IIE, polypeptide } \\
1 \text {, alpha } 56 \mathrm{kDa}\end{array}$ & 3.771876 & 0.000207 & 0.025791 \\
\hline LHFPL2 & $\begin{array}{l}\text { lipoma HMGIC fusion } \\
\text { partner-like } 2\end{array}$ & 3.773798 & 0.000206 & 0.025791 \\
\hline CD247 & CD247 molecule & 3.778095 & 0.000202 & 0.025791 \\
\hline TFG & TRK-fused gene & 3.78272 & 0.000199 & 0.02575 \\
\hline NKG7 & $\begin{array}{l}\text { natural killer cell group } \\
7 \text { sequence }\end{array}$ & 3.785842 & 0.000197 & 0.02575 \\
\hline PSME3 & $\begin{array}{l}\text { proteasome (prosome, } \\
\text { macropain) activator } \\
\text { subunit } 3 \text { (PA28 } \\
\text { gamma; Ki) }\end{array}$ & 3.78815 & 0.000195 & 0.02575 \\
\hline CD3D & $\begin{array}{l}\text { CD3d molecule, delta } \\
\text { (CD3-TCR complex) }\end{array}$ & 3.797803 & 0.000188 & 0.02575 \\
\hline GIN1 & $\begin{array}{l}\text { gypsy retrotransposon } \\
\text { integrase } 1\end{array}$ & 3.801631 & 0.000185 & 0.02575 \\
\hline PSMD7 & $\begin{array}{l}\text { proteasome (prosome, } \\
\text { macropain) } 26 \mathrm{~S} \\
\text { subunit, non-ATPase, } 7\end{array}$ & 3.811814 & 0.000178 & 0.025233 \\
\hline KPNA1 & $\begin{array}{l}\text { karyopherin alpha } 1 \\
\text { (importin alpha 5) }\end{array}$ & 3.815238 & 0.000176 & 0.025204 \\
\hline RAC2 & $\begin{array}{l}\text { ras-related C3 } \\
\text { botulinum toxin } \\
\text { substrate } 2 \text { (rho } \\
\text { family, small GTP } \\
\text { binding protein Rac2) }\end{array}$ & 3.81962 & 0.000173 & 0.025086 \\
\hline OSTF1 & $\begin{array}{l}\text { osteoclast stimulating } \\
\text { factor } 1\end{array}$ & 3.829957 & 0.000166 & 0.024712 \\
\hline AP1G1 & $\begin{array}{l}\text { adaptor-related } \\
\text { protein complex } 1, \\
\text { gamma } 1 \text { subunit }\end{array}$ & 3.832815 & 0.000164 & 0.024712 \\
\hline SLC30A5 & $\begin{array}{l}\text { solute carrier family } 30 \\
\text { (zinc transporter), } \\
\text { member } 5\end{array}$ & 3.832914 & 0.000164 & 0.024712 \\
\hline SLC31A2 & $\begin{array}{l}\text { solute carrier family } 31 \\
\text { (copper transporters), } \\
\text { member } 2\end{array}$ & 3.841574 & 0.000159 & 0.024712 \\
\hline FTSJ2 & FtsJ homolog 2 (E. coli) & 3.842267 & 0.000159 & 0.024712 \\
\hline SFT2D2 & $\begin{array}{l}\text { SFT2 domain } \\
\text { containing } 2\end{array}$ & 3.848055 & 0.000155 & 0.024712 \\
\hline $\mathrm{BGN}$ & biglycan & 3.851142 & 0.000153 & 0.024712 \\
\hline $\mathrm{DHODH}$ & $\begin{array}{l}\text { dihydroorotate } \\
\text { dehydrogenase }\end{array}$ & 3.853507 & 0.000152 & 0.024712 \\
\hline
\end{tabular}




\begin{tabular}{|c|c|c|c|c|}
\hline UNC50 & $\begin{array}{l}\text { unc-50 homolog (C. } \\
\text { elegans) }\end{array}$ & 3.870186 & 0.000142 & 0.024168 \\
\hline CCL5 & $\begin{array}{l}\text { chemokine (C-C motif) } \\
\text { ligand } 5\end{array}$ & 3.871711 & 0.000142 & 0.024168 \\
\hline KLHL18 & $\begin{array}{l}\text { kelch-like } 18 \\
\text { (Drosophila) }\end{array}$ & 3.873486 & 0.000141 & 0.024168 \\
\hline CFLAR & $\begin{array}{l}\text { CASP8 and FADD-like } \\
\text { apoptosis regulator }\end{array}$ & 3.875531 & 0.00014 & 0.024168 \\
\hline NAPA & $\begin{array}{l}\text { N-ethylmaleimide- } \\
\text { sensitive factor } \\
\text { attachment protein, } \\
\text { alpha }\end{array}$ & 3.877349 & 0.000139 & 0.024168 \\
\hline HS3ST3A1 & $\begin{array}{l}\text { heparan sulfate } \\
\text { (glucosamine) 3-O- } \\
\text { sulfotransferase 3A1 }\end{array}$ & 3.882571 & 0.000136 & 0.024168 \\
\hline SNX19 & sorting nexin 19 & 3.890749 & 0.000132 & 0.024168 \\
\hline ZDHHC4 & $\begin{array}{l}\text { zinc finger, DHHC-type } \\
\text { containing } 4\end{array}$ & 3.895902 & 0.000129 & 0.024168 \\
\hline CCR5 & $\begin{array}{l}\text { chemokine (C-C motif) } \\
\text { receptor } 5\end{array}$ & 3.895965 & 0.000129 & 0.024168 \\
\hline RPA3 & $\begin{array}{l}\text { replication protein } A 3 \text {, } \\
14 \mathrm{kDa}\end{array}$ & 3.896686 & 0.000129 & 0.024168 \\
\hline TFIP11 & $\begin{array}{l}\text { tuftelin interacting } \\
\text { protein } 11\end{array}$ & 3.899828 & 0.000127 & 0.024168 \\
\hline ZNF131 & zinc finger protein 131 & 3.915426 & 0.00012 & 0.024015 \\
\hline HLA-DPA1 & $\begin{array}{l}\text { major } \\
\text { histocompatibility } \\
\text { complex, class II, DP } \\
\text { alpha } 1\end{array}$ & 3.921252 & 0.000117 & 0.023876 \\
\hline CD48 & CD48 molecule & 3.923641 & 0.000116 & 0.023876 \\
\hline EWSR1 & $\begin{array}{l}\text { similar to Ewing } \\
\text { sarcoma breakpoint } \\
\text { region 1; Ewing } \\
\text { sarcoma breakpoint } \\
\text { region } 1\end{array}$ & 3.940633 & 0.000108 & 0.022918 \\
\hline PLAU & $\begin{array}{l}\text { plasminogen activator, } \\
\text { urokinase }\end{array}$ & 3.947267 & 0.000106 & 0.022732 \\
\hline MFN1 & mitofusin 1 & 3.961498 & $1.00 \mathrm{E}-04$ & 0.021893 \\
\hline TREX1 & $\begin{array}{l}\text { three prime repair } \\
\text { exonuclease } 1\end{array}$ & 3.978572 & $9.35 \mathrm{E}-05$ & 0.020854 \\
\hline AP1B1 & $\begin{array}{l}\text { adaptor-related } \\
\text { protein complex } 1 \text {, } \\
\text { beta } 1 \text { subunit }\end{array}$ & 3.997185 & 8.69E-05 & 0.019747 \\
\hline EVI2B & $\begin{array}{l}\text { ecotropic viral } \\
\text { integration site 2B }\end{array}$ & 4.002707 & $8.50 \mathrm{E}-05$ & 0.019694 \\
\hline GIMAP4 & $\begin{array}{l}\text { GTPase, IMAP family } \\
\text { member } 4\end{array}$ & 4.018092 & 8.00E-05 & 0.019262 \\
\hline GTF3C3 & $\begin{array}{l}\text { general transcription } \\
\text { factor IIIC, polypeptide } \\
3,102 \mathrm{kDa}\end{array}$ & 4.051625 & 7.01E-05 & 0.017948 \\
\hline TXNDC9 & $\begin{array}{l}\text { thioredoxin domain } \\
\text { containing } 9\end{array}$ & 4.05962 & 6.79E-05 & 0.017763 \\
\hline
\end{tabular}




\begin{tabular}{|c|c|c|c|c|}
\hline TCTA & $\begin{array}{l}\text { T-cell leukemia } \\
\text { translocation altered } \\
\text { gene }\end{array}$ & 4.070506 & $6.50 \mathrm{E}-05$ & 0.017385 \\
\hline ADAT1 & $\begin{array}{l}\text { adenosine deaminase, } \\
\text { tRNA-specific } 1\end{array}$ & 4.084569 & $6.14 \mathrm{E}-05$ & 0.017198 \\
\hline SNRK & SNF related kinase & 4.088061 & 6.06E-05 & 0.017198 \\
\hline ATR & $\begin{array}{l}\text { ataxia telangiectasia } \\
\text { and Rad3 related; } \\
\text { similar to ataxia } \\
\text { telangiectasia and } \\
\text { Rad3 related protein }\end{array}$ & 4.094535 & 5.90E-05 & 0.017198 \\
\hline SNAI2 & $\begin{array}{l}\text { snail homolog } 2 \\
\text { (Drosophila) }\end{array}$ & 4.100981 & 5.75E-05 & 0.017198 \\
\hline PSMB10 & $\begin{array}{l}\text { proteasome (prosome, } \\
\text { macropain) subunit, } \\
\text { beta type, } 10\end{array}$ & 4.104128 & $5.68 \mathrm{E}-05$ & 0.017198 \\
\hline GLRX & $\begin{array}{l}\text { glutaredoxin } \\
\text { (thioltransferase) }\end{array}$ & 4.117738 & 5.37E-05 & 0.017198 \\
\hline CEP63 & $\begin{array}{l}\text { centrosomal protein } \\
63 \mathrm{kDa}\end{array}$ & 4.123653 & $5.25 \mathrm{E}-05$ & 0.017198 \\
\hline RAB31 & $\begin{array}{l}\text { RAB31, member RAS } \\
\text { oncogene family }\end{array}$ & 4.123728 & $5.25 \mathrm{E}-05$ & 0.017198 \\
\hline MYCBP & c-myc binding protein & 4.141877 & 4.87E-05 & 0.017198 \\
\hline CD53 & CD53 molecule & 4.153208 & 4.66E-05 & 0.017198 \\
\hline APOL6 & apolipoprotein L, 6 & 4.168263 & $4.38 \mathrm{E}-05$ & 0.017013 \\
\hline TPST2 & $\begin{array}{l}\text { tyrosylprotein } \\
\text { sulfotransferase } 2\end{array}$ & 4.186272 & 4.07E-05 & 0.016335 \\
\hline LIPT1 & lipoyltransferase 1 & 4.211462 & 3.67E-05 & 0.015243 \\
\hline CD2 & CD2 molecule & 4.214681 & 3.62E-05 & 0.015243 \\
\hline MRPS30 & $\begin{array}{l}\text { mitochondrial } \\
\text { ribosomal protein \$30 }\end{array}$ & 4.266927 & $2.92 \mathrm{E}-05$ & 0.013025 \\
\hline CYB561D2 & $\begin{array}{l}\text { cytochrome b-561 } \\
\text { domain containing } 2\end{array}$ & 4.291059 & 2.64E-05 & 0.012236 \\
\hline ARF4 & $\begin{array}{l}\text { ADP-ribosylation } \\
\text { factor } 4\end{array}$ & 4.293031 & $2.62 \mathrm{E}-05$ & 0.012236 \\
\hline CD52 & CD52 molecule & 4.295198 & 2.60E-05 & 0.012236 \\
\hline IFI30 & $\begin{array}{l}\text { interferon, gamma- } \\
\text { inducible protein } 30\end{array}$ & 4.296248 & $2.59 \mathrm{E}-05$ & 0.012236 \\
\hline NUP155 & nucleoporin $155 \mathrm{kDa}$ & 4.323515 & $2.31 \mathrm{E}-05$ & 0.012236 \\
\hline PRKAA1 & $\begin{array}{l}\text { protein kinase, AMP- } \\
\text { activated, alpha } 1 \\
\text { catalytic subunit }\end{array}$ & 4.327062 & 2.27E-05 & 0.012236 \\
\hline PTPRC & $\begin{array}{l}\text { protein tyrosine } \\
\text { phosphatase, receptor } \\
\text { type, C }\end{array}$ & 4.354332 & 2.03E-05 & 0.012207 \\
\hline ETF1 & $\begin{array}{l}\text { eukaryotic translation } \\
\text { termination factor } 1\end{array}$ & 4.375175 & $1.86 \mathrm{E}-05$ & 0.012207 \\
\hline ASCC3 & $\begin{array}{l}\text { activating signal } \\
\text { cointegrator } 1 \text { complex } \\
\text { subunit } 3\end{array}$ & 4.394201 & $1.71 \mathrm{E}-05$ & 0.012207 \\
\hline $\mathrm{HCCS}$ & $\begin{array}{l}\text { holocytochrome c } \\
\text { synthase (cytochrome }\end{array}$ & 4.447838 & $1.36 \mathrm{E}-05$ & 0.011155 \\
\hline
\end{tabular}




\begin{tabular}{|c|c|c|c|c|}
\hline & c heme-lyase) & & & \\
\hline ZBTB11 & $\begin{array}{l}\text { zinc finger and BTB } \\
\text { domain containing } 11\end{array}$ & 4.566012 & $8.18 \mathrm{E}-06$ & 0.008959 \\
\hline SPCS1 & $\begin{array}{l}\text { signal peptidase } \\
\text { complex subunit } 1 \\
\text { homolog (S. cerevisiae) }\end{array}$ & 4.605288 & $6.89 \mathrm{E}-06$ & 0.008299 \\
\hline EIF2B3 & $\begin{array}{l}\text { eukaryotic translation } \\
\text { initiation factor 2B, } \\
\text { subunit } 3 \text { gamma, } \\
58 \mathrm{kDa}\end{array}$ & 4.614382 & $6.62 \mathrm{E}-06$ & 0.008299 \\
\hline GMPPB & $\begin{array}{l}\text { GDP-mannose } \\
\text { pyrophosphorylase B }\end{array}$ & 4.693984 & 4.66E-06 & 0.007008 \\
\hline LCP2 & $\begin{array}{l}\text { lymphocyte cytosolic } \\
\text { protein } 2 \text { (SH2 domain } \\
\text { containing leukocyte } \\
\text { protein of } 76 \mathrm{kDa})\end{array}$ & 4.742966 & $3.74 \mathrm{E}-06$ & 0.006434 \\
\hline GMDS & $\begin{array}{l}\text { GDP-mannose 4,6- } \\
\text { dehydratase }\end{array}$ & 4.755461 & $3.54 \mathrm{E}-06$ & 0.006434 \\
\hline SAMSN1 & $\begin{array}{l}\text { SAM domain, } \mathrm{SH} 3 \\
\text { domain and nuclear } \\
\text { localization signals } 1\end{array}$ & 4.868034 & $2.12 \mathrm{E}-06$ & 0.00511 \\
\hline VAMP3 & $\begin{array}{l}\text { vesicle-associated } \\
\text { membrane protein } 3 \\
\text { (cellubrevin) }\end{array}$ & 5.101483 & $7.16 \mathrm{E}-07$ & 0.002154 \\
\hline ASL & argininosuccinate lyase & 5.312724 & $2.59 \mathrm{E}-07$ & 0.001041 \\
\hline YIPF5 & $\begin{array}{l}\text { Yip1 domain family, } \\
\text { member } 5\end{array}$ & 5.436012 & $1.41 \mathrm{E}-07$ & 0.000851 \\
\hline CASP1 & $\begin{array}{l}\text { caspase } 1 \text {, apoptosis- } \\
\text { related cysteine } \\
\text { peptidase (interleukin } \\
1 \text {, beta, convertase) }\end{array}$ & 5.72215 & 3.34E-08 & 0.000402 \\
\hline
\end{tabular}




\title{
Obesity increases tumor aggressiveness in a genetically engineered mouse model of serous ovarian cancer ${ }^{\text {th }}$
}

\author{
Liza Makowski a,b,1 , Chunxiao Zhou ${ }^{c}$, Yan Zhong ${ }^{c}$, Pei Fen Kuan ${ }^{\text {b,d }}$, Cheng Fan ${ }^{\text {b }}$, Brante P. Sampey ${ }^{\mathrm{e}}$, \\ Megan Difurio ${ }^{\mathrm{f}}$, Victoria L. Bae-Jump ${ }^{\mathrm{b}, \mathrm{c}, *, 2}$ \\ a Department of Nutrition, University of North Carolina, Chapel Hill, NC, USA \\ ${ }^{\mathrm{b}}$ Lineberger Comprehensive Cancer Center, University of North Carolina, Chapel Hill, NC, USA \\ c Division of Gynecologic Oncology, University of North Carolina, Chapel Hill, NC, USA \\ d Department of Biostatistics, University of North Carolina, Chapel Hill, NC, USA \\ e Metabolon, Inc., Durham, NC, USA \\ ${ }^{\mathrm{f}}$ Department of Pathology and Laboratory Medicine, University of North Carolina, Chapel Hill, NC, USA
}

\section{H I G H L I G H T S}

- Obesity promotes tumor progression in the KpB mouse model of serous ovarian cancer.

- Gene expression and metabolomic profiling indicated significant differences between ovarian tumors from obese versus non-obese mice, including metabolically relevant pathways.

\section{A R T I C L E I N F O}

\section{Keywords:}

Obesity

Ovarian cancer

Mouse model

Metabolomics

Genomics

Biomarkers

\section{A B S T R A C T}

Objectives. Obesity is associated with increased risk and worse outcomes for ovarian cancer. Thus, we examined the effects of obesity on ovarian cancer progression in a genetically engineered mouse model of serous ovarian cancer.

Methods. We utilized a unique serous ovarian cancer mouse model that specifically deletes the tumor suppressor genes, Brca1 and p53, and inactivates the retinoblastoma $(\mathrm{Rb})$ proteins in adult ovarian surface epithelial cells, via injection of an adenoviral vector expressing Cre (AdCre) into the ovarian bursa cavity of adult female mice (KpB mouse model). $\mathrm{KpB}$ mice were subjected to a $60 \%$ calories-derived from fat in a high fat diet (HFD) versus $10 \%$ calories from fat in a low fat diet (LFD) to mimic diet-induced obesity. Tumors were isolated at 6 months after AdCre injection and evaluated histologically. Untargeted metabolomic and gene expression profiling was performed to assess differences in the ovarian tumors from obese versus non-obese KpB mice.

Results. At sacrifice, mice on the HFD (obese) were twice the weight of mice on the LFD (non-obese) ( $51 \mathrm{~g}$ versus $31 \mathrm{~g}, \mathrm{p}=0.0003$ ). Ovarian tumors were significantly larger in the obese versus non-obese mice ( $3.7 \mathrm{~cm}^{2}$ versus $1.2 \mathrm{~cm}^{2}, \mathrm{p}=0.0065$ ). Gene expression and metabolomic profiling indicated statistically significant differences between the ovarian tumors from the obese versus non-obese mice, including metabolically relevant pathways.

(c) 2013 Elsevier Inc. All rights reserved.

\footnotetext{
Presented as an oral presentation at the 2013 Annual Meeting of the Society of Gynecologic Oncology in Los Angeles, CA.

* Corresponding author at: University of North Carolina (UNC), Division of Gynecologic Oncology, CB\# 7572, Physicians Office Building Rm\# B105, Chapel Hill, NC 27599, USA. Fax: + 19198435387

E-mail address: victoria_baejump@med.unc.edu (V.L. Bae-Jump).

1 LM was supported by UNC University Cancer Research Fund, NIH AA017376; NIH ES019472; NIH P30DK056350 - Nutrition Obesity Research Consortium (NORC)

2 VBJ was supported by Gynecologic Cancer Foundation/Florence \& Marshall Schwid Ovarian Cancer Research Grant, The North Carolina Translational and Clinical Sciences Institute/NC TraCS $\$ 50 \mathrm{~K}$ Pilot Grant Program, National Institutes of Health Grant DK056350 to the UNC Nutrition Obesity Research Center, OC110163 Department of Defense/Ovarian Cancer Research Program (DOD/OCRP) Translational Pilot Award.
}

\section{Introduction}

Obesity has been linked to increased risk of many cancers, including breast, colon, endometrial, among others [1]. Currently, new cancer cases are in the order of 1.5 million with half a million cancer deaths per year, and nearly one in five are due to obesity $[1,2]$. It is postulated that hyperglycemia and hyperinsulinemia resulting from overnutrition in obese patients provide abundant nutrients and growth factors to cancer cells, resulting in the ideal environment for tumor initiation and promotion [3]. Chronic inflammation and immunosuppression are also thought to be a link between obesity and cancer [3]. 
Epithelial ovarian cancer (OC) is one of the most deadly cancers with an overall 5-year survival of only 30-40\%. Increasing evidence suggests that obesity is a significant risk factor for $\mathrm{OC}$ and associated with worse outcomes for this disease [1,4-20]. Given the overall poor prognosis of $\mathrm{OC}$ and the rising rate of obesity, it is imperative to investigate obesity as a potential modifiable risk factor that may reverse risk and lead to the prevention and improvement of outcomes for OC. We hypothesize that the metabolic consequences of obesity may play a contributing role in the pathogenesis of OC and may lead to biologically and phenotypically different cancers than those that arise in normal weight women, possibly necessitating distinct treatment strategies. Herein, we assessed the impact of obesity on OC development and progression in a genetically engineered mouse model of serous OC and comprehensively interrogated the obesity-induced carcinogenesis signature through genomic and metabolomic analysis.

\section{Materials and methods}

Obesity and the $\mathrm{K} 18-\mathrm{g} \mathrm{T}_{121}^{+/-} ; \mathrm{p} 53^{f l / f l} ; \mathrm{Brca1}^{f l / f l}$ mouse model

The $\mathrm{K} 18-\mathrm{gT}_{121}^{+/-} ; \mathrm{p} 53^{\mathrm{fl} / \mathrm{fl}} ; \mathrm{Brca}^{\mathrm{fl} / \mathrm{fl}}(\mathrm{KpB})$ mouse model (Terry Van Dyke, $\mathrm{PhD}, \mathrm{NIH}$ ) is a unique serous OC mouse model, wherein the tumor suppressor genes, Brca1 and p53 are specifically and somatically deleted and the retinoblastoma $(\mathrm{Rb})$ proteins are inactivated in the adult ovarian surface epithelium [21]. Inactivation of all $3 \mathrm{Rb}$ proteins by $\mathrm{T}_{121}$ (a fragment of the SV40 large T antigen) is driven by the keratin 18 (K18) promoter [21]. Expression of the $\mathrm{T}_{121}$ transgene and knockout of p53 and Brca1 are conditional and only activated via injection of an adenoviral vector expressing Cre (AdCre) into the ovarian bursa cavity of adult female mice. At approximately 6 months after AdCre injection, tumors develop in the affected ovary, while the un-injected ovary remains normal.

All experimental animals were maintained in accordance with the Institutional Animal Care and Use Committee (IACUC) and the $\mathrm{NIH}$ guide for the Care and Use of Laboratory Animals. Recombinant adenovirus Ad5-CMV-Cre (AdCre) was purchased from the University of Iowa Transfer Vector Core at a titer of $10^{11}-10^{12}$ infectious particles/ml. To maximize weight gain, mice were provided a high-fat diet (HFD, obese group) (60\% kcal from fat, Research Diets, New Brunswick, NJ) and control mice (non-obese group) were provided a low-fat diet (LFD) (10\% kcal from fat, Research Diets, New Brunswick, NJ) ad libitum, beginning at 6 weeks of age. AdCre injection occurred at 8 weeks to induce OC 6 months later (at 8 months of age) [21]. Thirty-six hours following superovulation, the mice were anesthetized, and a single $1 \mathrm{~cm}$ incision was made on the dorsal surface of each mouse. The AdCre was then injected via a needle introduced into the oviduct near the infundibulum and into the ovarian bursa, and the incision was closed. All mice were sacrificed at 8 months of age.

The primary outcome comparison between non-obese and obese mice was the response of tumor growth to the obesity exposure. This was assessed via direct measurement of the tumor at the time of sacrifice. At the time of sacrifice, the ovarian tumors were harvested, wet tumor weights recorded, and tissue was snap frozen in liquid nitrogen for later harvest of mRNA for microarray analysis and metabolites for metabolomic analysis.

\section{Body weight E' composition}

Prior to starting mice on diet and weekly until sacrifice, body weight was measured. Body composition, including lean mass, fat mass, free water content and total water content, of non-anesthetized mice was also measured at pre- and post-diet exposures using the EchoMRI-100 quantitative magnetic resonance whole body composition analyzer (Echo Medical Systems, Houston, TX).

\section{Blood glucose}

Random blood glucose was measured prior to start of diet and at sacrifice using a Bayer Contour Blood Glucose Monitor (Bayer HealthCare LLC, Tarrytown, NY).

mRNA isolation

Approximately 25-50 mg of frozen OC tissue in small fragments was homogenized in RLT lysis buffer. Total RNA was isolated using the RNeasy mini kit and QIAshredder kit (Qiagen Inc., Mississauga, ON) following the manufacturer's instructions. RNA quantity and quality were analyzed by Nanodrop (Thermoscientific, Wilmington, DE).

\section{Gene expression profiling}

Microarrays were performed on ovarian tumors from non-obese and obese mice ( $\mathrm{N}=5$ /group) using Affymetrix GeneChip Mouse Genome 4302.0 Arrays. These samples were processed in the Lineberger Comprehensive Cancer Center Genomics Core Facility. The image files were analyzed with GenePix Pro 4.1 and pre-processed via the UNC-Chapel Hill Microarray Database (https://genome.unc.edu) where a Lowess normalization procedure was performed to adjust for $\mathrm{Cy} 3$ and $\mathrm{Cy} 5$ channel biases [22]. In addition, probes with missing values in 3 or more samples in each of the obese and non-obese groups were removed. Two-class SAM (Significance Analysis of Microarrays, http://www-stat. stanford.edu/ tibs/SAM/) was performed to identify significantly differentially expressed genes using FDR $<0.2$. EASE (Expression Analysis Systematic Explorer, http://david.niaid.nih.gov/david/ease.htm) analysis was used to interpret and identify biological themes (gene ontology categories) overrepresented in the gene list obtained from SAM results. The EASE Score was used as statistical measure of overrepresentation of a biological theme. Specifically, the EASE Score is a jackknifed one-tailed Fisher's exact probability which is calculated by removing one gene within the given category from the list and penalizes the statistical significance of categories supported by fewer genes; thus is a more robust measure than the Fisher's exact probability [23].

\section{Metabolomic profiling}

Gas chromatography time-of-flight mass spectrometry (GC-TOFMS, Leco Corporation, St Joseph, MI) and liquid chromatography coupled with time-of-flight mass spectrometry (LC-TOFMS, Agilent Corporation, Santa Clara, CA) were used to analyze tumors from non-obese and obese mice ( $N=5 /$ group). Metabolite extraction followed previous publication with minor revision through the UNC/Nutrition Obesity Research Center (NORC) Core facility [24]. Briefly, $50 \mathrm{mg}$ samples were extracted with $0.5 \mathrm{ml}$ of methanol:chloroform:water $=3: 1: 1(\mathrm{v}: \mathrm{v}: \mathrm{v})$ with homogenization for $3 \mathrm{~min}$ using 1-mm inner diameter balls in a Bullet Blender (Next Advance, Averill Park, NY). Two aliquots of $150 \mu \mathrm{l}$ of supernatant were used for GC-TOFMS and LC-TOFMS analysis, separately. After removal of the extra supernatant, the remainder was extracted with $500 \mu \mathrm{l}$ of methanol. Two aliquots of $150 \mu \mathrm{l}$ of supernatant were combined into the tube containing first step extraction for GC and LC-TOFMS analysis, separately. Metabolite annotation was performed by comparing the mass spectrum and retention time to an inhouse library and NIST library (GC-TOMFS) or HMDB (LC-TOFMS) $[25,26]$.

\section{Statistical methods}

Unpaired Student's t-test was used to determine statistical difference between non-obese and obese treatment groups using STATA software (College Station, TX). A p-value $<0.05$ was considered significant. For metabolomics, after normalization to the internal standard and sample weight, the data set was imported into SIMCA-p software 
(Umeå, Sweden) for multivariate analysis. Principle component analysis (PCA) was first performed to check the outliers and the separation tendency (data not shown). A supervised orthogonal partial least squares-discriminant analysis (OPLS-DA) analysis was then performed. Differentiating metabolites were selected with the criteria of the variable importance in the projection (VIP) value $>1$ and $p$ value (Student's $t$ test) lower than 0.05 .

\section{Results}

\section{Obesity drove significant tumor progression in $\mathrm{KpB}$ mice}

$\mathrm{KpB}$ mice were subjected to $60 \%$ calories-derived from fat in a high fat diet (HFD) versus $10 \%$ calories from fat in a low fat diet (LFD) to induce diet-induced obesity ( $\mathrm{N}=14 /$ group) starting at 6 weeks of age and until sacrifice. After 8 months of exposure to the HFD or LFD, obese mice weighed significantly greater than non-obese mice ( $p=0.003$, Table 1$)$. There was no effect of HFD on non-fasted blood glucose levels in KpB mice over the course of the diet (Table 1). Body composition was significantly altered in obese $\mathrm{KpB}$ mice compared to non-obese controls. Percent body fat was six-fold greater in obese mice (Table $1, p=0.0001$ ), while percent lean mass increased by $25 \%$ ( $p=0.0006$, Table 1$)$. The ovarian tumors were tripled in size in the obese mice as compared to non-obese mice (mean size of $3.7 \mathrm{~cm}^{2}$ versus $1.2 \mathrm{~cm}^{2}$, Fig. $1, \mathrm{p}=0.0065$ ).

Obesity induces genomic differences between obese and non-obese ovarian tumors

439 genes were found to be significantly up-regulated ( 417 genes) or down-regulated ( 22 genes) in the ovarian tumors from obese KpB mice versus non-obese mice (FDR $<0.2$, Supplemental Table 1 ). Fig. 2 is a heat map of 131 genes up- and down-regulated at a FDR $<0.1$. Metabolically relevant genes were significantly upregulated in the ovarian tumors from the obese versus non-obese mice, such as lipocalin (2.7 fold), fatty acid amide hydrolase (2.7 fold), fatty acid 2-hydroxylase (2.2 fold), glycerol-3-phosphate acyltransferase ( 1.5 fold), protein phosphatase (1.2 fold), AMP deaminase 3 (1.6 fold), and protein kinase C (1.7 fold) (Supplemental Table 1). Arginase 1 was the most upregulated gene ( 7.3 fold) and plays a role in the urea cycle, tissue remodeling and inflammation. Other upregulated genes identified in the ovarian tumors from the obese mice were related to cell adhesion, including neurotrimin (2.2 fold) and desmoglein 1-alpha (2.0 fold). Increased expression of histone 1 ( 2.3 fold), endothelin-1 (5.8 fold), ectonucleoside triphosphate diphosphohydrolase ( 3 fold) and serotonin transporter solute carrier family 6 member 4 (Slc6a4) (5.4 fold) were also associated with obesity in the KpB mouse model. Significantly downregulated genes with obesity included spermidine synthase and thrombospondin 4.

In the ovarian tumors from the obese versus non-obese mice, EASE over-representation analysis revealed significant enrichment in "phospholipid binding" (EASE score of 0.008), "regulation of apoptosis" (EASE score of 0.014), "lipid binding” (EASE score of 0.015), "endopeptidase activity" (EASE score of 0.03) and "cell-cell signaling" (EASE score of 0.44 ) for those identified genes.

Table 1

Diet-induced metabolic characteristics in non-obese and obese $\mathrm{KpB}$ mice.

\begin{tabular}{lccl}
\hline & Non-obese & Obese & p-Value \\
\hline Weight $(\mathrm{g})$ & $31.14 \pm 5.26$ & $50.71 \pm 16.73$ & $\mathrm{p}=0.0003$ \\
Glucose $(\mathrm{mg} / \mathrm{dl})$ & $186.81 \pm 26.99$ & $214.38 \pm 58.11$ & $\mathrm{p}=0.053$ \\
\% fat & $3.28 \pm 1.51$ & $19.58 \pm 7.88$ & $\mathrm{p}=0.00001$ \\
$\%$ lean & $22.89 \pm 2.11$ & $28.66 \pm 5.24$ & $\mathrm{p}=0.0006$ \\
\hline
\end{tabular}

$\mathrm{N}=14$ mice per group. Mean $\pm \mathrm{SD}$. \% fat or \% lean = each mass / total body mass as measured by MRI.
Metabolic differences between ovarian tumors from obese and non-obese KpB mice

Principle component analysis defined a clear separation between obese and non-obese samples (Fig. 3, 3 components, $\mathrm{R} 2 \mathrm{X}=0.563$, $\mathrm{R} 2$ Ycum $=0.95$, Q2cum $=0.411$ ). Differentiating metabolites were selected with the criteria of the variable importance in the projection (VIP) value $>1$ and $p$ value (Student's $t$ test) lower than 0.05 . Twenty metabolites were identified using this criterion, all of which were upregulated in the ovarian tumors of the non-obese versus obese $\mathrm{KpB}$ mice (Table 2).

Metabolites involved in inflammatory signaling and protein/collagen metabolism were down-regulated in the ovarian tumors of obese mice as compared to non-obese mice, including arginine ( $\mathrm{p}=0.0268), \mathrm{N}$ glycylproline $(\mathrm{p}=0.0043)$ and 3-amino-2-piperidone $(\mathrm{p}=0.0099)$. Components and markers of oxidative stress were also downregulated in the tumors from obese mice: glutathione ( $p=0.0313)$, oxidized glutathione $(\mathrm{p}=0.0047)$, gluconolactone $(\mathrm{p}=0.0311)$ and 8-hydroxydeoxyguanosine $(\mathrm{p}=0.0230)$. Lower levels of nucleotides (i.e. cytidine ( $p=0.0122$ and $p=0.0424)$, cytosine $(p=0.0158)$, guanosine diphosphate (GDP, $\mathrm{p}=0.0404)$ ) and adenosine monophosphate (AMP, $\mathrm{p}=0.0257$ ) were detected with obesity. The serotonin metabolite, 5hydroxyindoleacetic acid (5HIAA, p = 0.0498), and the catecholamine metabolites, vanillactic acid $(\mathrm{p}=0.0079)$ and phenylethanolamine ( $p=0.0446$ ), were found to be lower in the ovarian tumors of obese versus non-obese mice. Glutamate $(\mathrm{p}=.0318)$, N-acetylaspartic acid $(p=0.0059)$ and succinic acid $(p=0.0465)$ are involved in energy metabolism, and were decreased in the ovarian tumors of obese KpB mice. $\operatorname{LysoPC}(16: 1(9 Z))(p=0.0205)$, a lysophospholipid, was also lower in the ovarian tumors from obese animals.

\section{Discussion}

Recent evidence suggests that obesity may be a significant risk factor and associated with worse outcomes for OC [1,4-20]. Therefore, a metabolic approach to the diagnosis and treatment of OC may provide a novel strategy to improve outcomes for this invariably lethal disease. Hence, we induced obesity in the KpB mouse, a faithful murine model of serous $\mathrm{OC}$, to ask if obesity alters tumorigenesis. $\mathrm{KpB}$ mice fed a HFD had significant increases in their body weight and fat mass compared to mice fed a LFD. Herein, we report that obesity promoted tumor progression in the $\mathrm{KpB}$ mouse model of $\mathrm{OC}$ with a tripling of ovarian tumor size. Obesity has been associated with more rapid tumor growth in animal models of other cancer types, such as breast, colon and lung cancer $[27,28]$, but this is the first study to demonstrate this for OC.

Genomic and metabolomic analyses were utilized to identify obesity-induced alterations in tumors with the intention of identifying significant pathways or biomarkers to aid in explaining why obese mice developed larger, more aggressive tumors. The metabolically relevant genes, lipocalin, ectonucleoside triphosphate diphosphohydrolase and fatty acid amide hydrolase, were upregulated in the ovarian tumors from the obese versus non-obese mice. Lipocalin, particularly lipocalin 2 , has been previously found to be upregulated in number of different cancers, including OCs $[29,30]$. The primary function of lipocalin is the transport of small ligands such as steroids, bilins, retinoids and lipids. In addition to its role in lipid transport, lipocalin has also been implicated in the inflammatory response. Another gene significantly upregulated was ectonucleoside triphosphate diphosphohydrolase, which is involved in the extracellular hydrolysis of ATP to generate adenosine, which signals through $\mathrm{G}$-protein coupled receptors and regulates metabolic pathways and inflammation. Chronic inflammation is well known to play a role in obesity-driven cancers which could also explain the increased expression of both lipocalin and ectonucleoside triphosphate diphosphohydrolase in the ovarian tumors of obese KpB mice. 

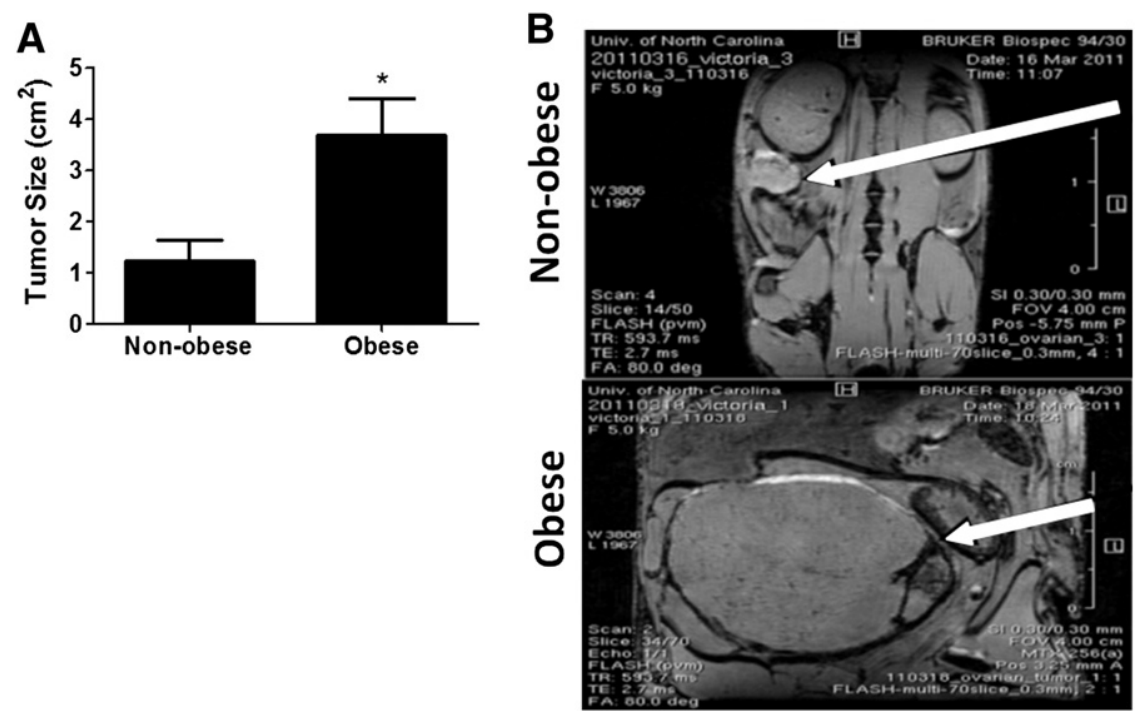

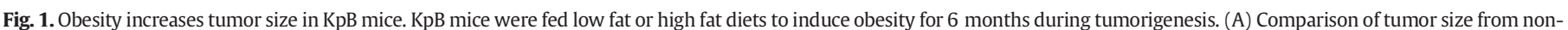

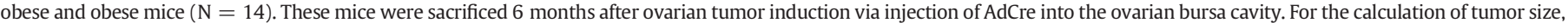

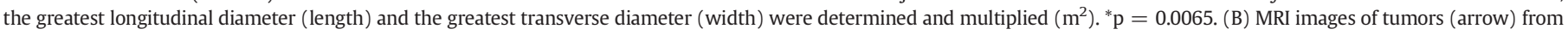
non-obese (top image) and obese (bottom image) mice demonstrate representative tumors.

Fatty acid amide hydrolase (FAAH) is a serine hydrolase that metabolizes $\mathrm{N}$-acylethanolamines (i.e. $\mathrm{N}$-arachidonoylethanolamine, $\mathrm{N}$-oleoylethanolamine and $\mathrm{N}$-palmitoylethanolamine), also known as endocannabinoids, to fatty acids plus ethanolamine. The endocannabinoid system is thought to be important in the regulation of cancer cell apoptosis, proliferation, migration, adhesion and invasion. Increased expression of the cannabinoid receptors (CB1R and CB2R) and FAAH has been documented in prostate and breast cancer and has been associated with worse outcomes [31]. FAAH inhibitors are under development for the treatment of pain and inflammation [31], but may also be useful in cancer. Our data suggests that FAAH inhibitors might be a potential targeted agent for obesity-driven cancers.

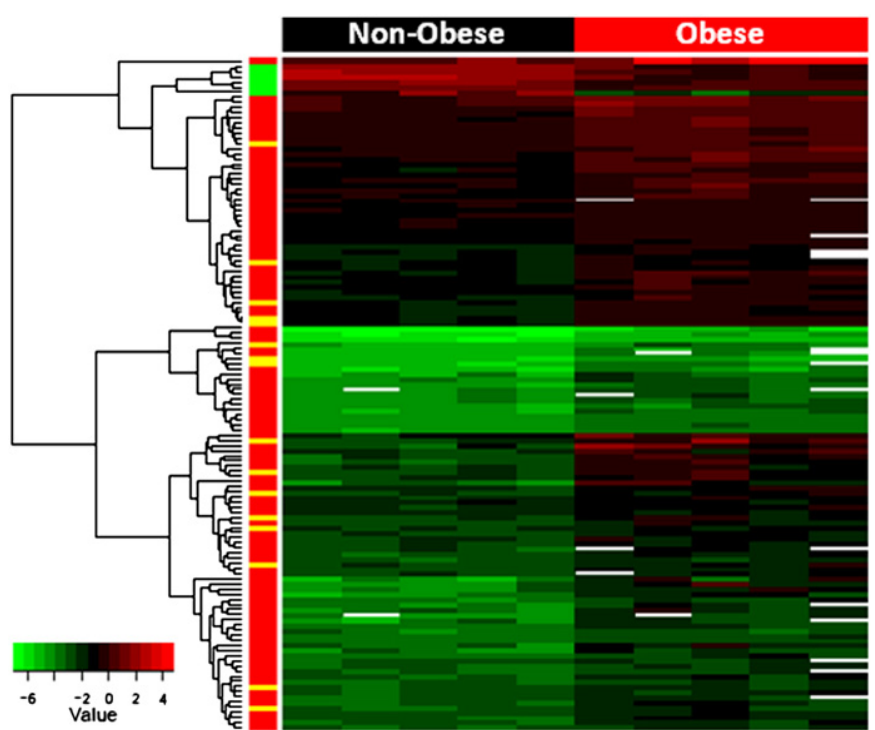

Fig. 2. Genomic differences between ovarian tumors from obese versus non-obese KpB mice reveal alterations in metabolically relevant genes. Heat map representation of 131 genes found to be significantly up- or down-regulated in the ovarian tumors from the obese versus non-obese $\mathrm{KpB}$ mice (FDR $<0.1)$. Many metabolically relevant genes, such as lipocalin, fatty acid amide hydrolase, ectonucleoside triphosphate diphosphohydrolase, fatty acid 2-hydroxylase, glycerol-3-phosphate acyltransferase, protein phosphatase, protein kinase $\mathrm{C}$ and AMP deaminase 3, were upregulated in obese tumors.
Other unique, metabolically relevant genes that were associated with obesity and $\mathrm{OC}$ development in the $\mathrm{KpB}$ mouse model included fatty acid 2-hydroxylase, glycerol-3-phosphate acyltransferase, protein phosphatase, protein kinase $C$ and AMP deaminase. Fatty acid 2-hydroxylase (FA2H) catalyzes the synthesis of 2-hydroxysphingolipids, a subset of sphingolipids that contain 2-hydroxy fatty acids. FA2H is thought to be involved in the cell differentiation of Schwann cells, keratinocytes and adipocytes. Glycerol-3-phosphate acyltransferase is an enzyme that participates in glycerolipid metabolism and glycerophospholipid metabolism. Protein phosphatases are essential to protein phosphorylation, an important form of reversible protein posttranslational modification involved in cell signaling cascades. The protein kinase C (PKC) family represents a number of protein kinase enzymes that are involved in regulating the function of other proteins through the phosphorylation

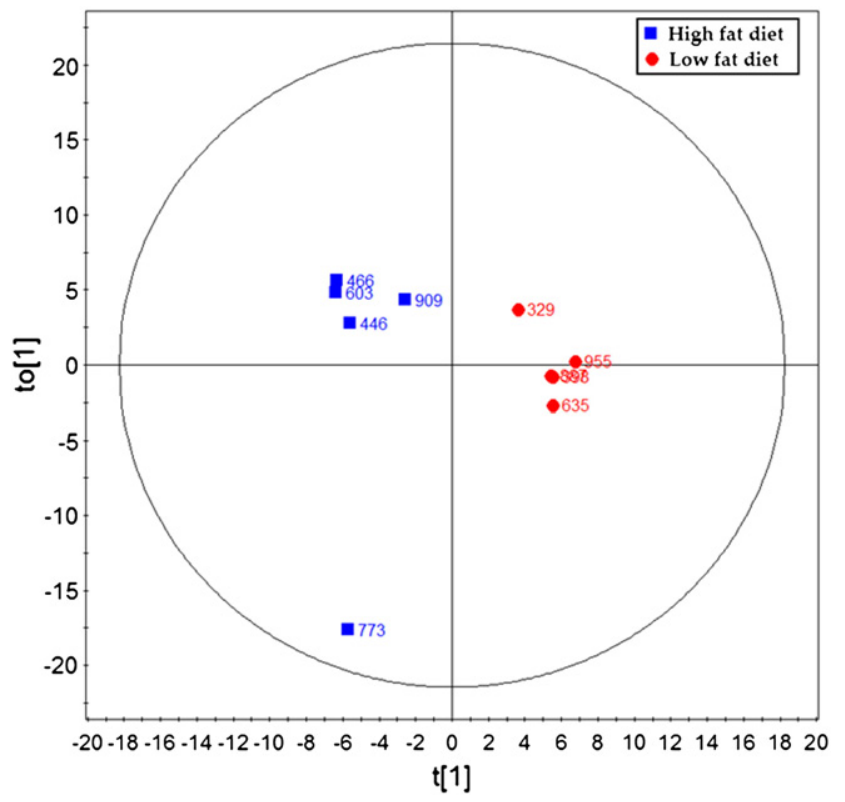

Fig. 3. Several metabolites define a clear separation using principal component analysis between the ovarian tumors in the non-obese group and obese group. PLS-DA scores plot of the ovarian tumors in the non-obese group (low fat diet) and obese (high fat diet) group. 
Table 2

Metabolic alterations in tumors from non-obese and obese KpB mice.

\begin{tabular}{|c|c|c|c|c|c|}
\hline Compound name & $\mathrm{VIP}^{\mathrm{a}}$ & $\mathrm{p}^{\mathrm{b}}$ & Fold change (non-obese/obese) ${ }^{c}$ & Analysis method & Identification method $^{\mathrm{d}}$ \\
\hline N-glycylproline & 2.27 & 0.0043 & 1.95 & LC-ES+ & Std \\
\hline Oxidized glutathione & 2.25 & 0.0047 & 3.45 & LC-ES+ & Std \\
\hline $\mathrm{N}$-acetylaspartic acid & 2.22 & 0.0059 & 2.31 & LC-ES- & HMDB \\
\hline Vanillactic acid & 2.17 & 0.0079 & 2.23 & LC-ES+ & HMDB \\
\hline 3-Amino-2-piperidone & 2.14 & 0.0099 & 1.75 & GCTOF & NIST \\
\hline Cytidine & 2.10 & 0.0122 & 4.52 & LC-ES+ & Std \\
\hline Cytosine & 2.05 & 0.0158 & 4.11 & LC-ES+ & Std \\
\hline LysoPC(16:1(9Z)) & 1.99 & 0.0205 & 1.83 & LC-ES+ & HMDB \\
\hline 8-Hydroxy-deoxyguanosine & 1.97 & 0.0230 & 2.45 & LC-ES+ & HMDB \\
\hline Adenosine monophosphate & 1.94 & 0.0257 & 1.61 & LC-ES- & HMDB \\
\hline Arginine & 1.93 & 0.0268 & 1.93 & LC-ES+ & Std \\
\hline Gluconolactone & 1.89 & 0.0311 & 2.97 & LC-ES+ & Std \\
\hline Glutathione & 1.89 & 0.0313 & 3.10 & LC-ES+ & Std \\
\hline Glutamate & 1.89 & 0.0318 & 1.52 & GCTOF & Std \\
\hline Guanosine diphosphate & 1.82 & 0.0404 & 2.39 & LC-ES- & HMDB \\
\hline Cytidine & 1.81 & 0.0424 & 4.97 & GCTOF & NIST \\
\hline Inodxyl glucuronide & 1.80 & 0.0439 & 3.05 & LC-ES+ & HMDB \\
\hline Phenylethanolamine & 1.80 & 0.0446 & 1.69 & GCTOF & NIST \\
\hline Succinic acid & 1.78 & 0.0465 & 1.90 & GCTOF & Std \\
\hline 5-Hydroxyindoleacetic acid & 1.76 & 0.0498 & 1.85 & LC-ES+ & HMDB \\
\hline
\end{tabular}

a Variable importance in the projection (VIP) was obtained from OPLS-DA with a threshold of 1.0.

b $\mathrm{p}$ value was calculated from Student's $t$ test.

c Fold change with a value larger than 1 indicates a relatively higher concentration in tumors from non-obese (low fat diet-fed) KpB mice, while a value less than 1 means a relatively lower concentration as compared to tumors from obese (high fat diet-fed) KpB mice.

d The metabolites were identified by in-house library (Std), NIST library (NIST) or HMBD database (HMDB).

of hydroxyl groups of serine and threonine amino acid residues on these proteins. The PKC family of enzymes has been implicated in the regulation of signal transduction, cell proliferation, metabolism and differentiation through its effects on regulation of the cell cycle. PKC inhibitors are already being evaluated in clinical trials for a variety of different cancers, including OC [32]. AMP deaminase 3 is a highly regulated enzyme that catalyzes the hydrolytic deamination of adenosine monophosphate to inosine monophosphate, a branch point in the adenylate catabolic pathway. AMP deaminase 3 is thought to be a potent regulator of energy metabolism in cells. Increased expression of AMP deaminases has been documented in hepatocellular carcinomas [33] but has not been explored in OC.

Although many metabolically relevant genes were found to be associated with obesity-driven cancers in the KpB mouse model, other upregulated genes and pathways were identified. This included genes related to cell adhesion, including neurotrimin and desmoglein 1alpha. Expression of neurotrimin and desmoglein 1-alpha has not been previously documented in OCs. Increased expression of histone 1 in the ovarian tumors was also associated with obesity in the $\mathrm{KpB}$ mice. Histones are the chief protein component of chromatin and are critical for gene regulation. Endothelin-1 (ET-1) is a highly potent vasoconstrictive peptide and was found to be upregulated 5.8 fold in the ovarian tumors from obese mice. Overexpression of ET-1 has been implicated in the epithelial-mesenchymal transition, a mechanism by which transformed epithelial cells acquire the ability to proliferate, invade, resist apoptosis and metastasize [34]. In chemoresistant ovarian cancer cells, ET-1 has been found to be upregulated, leading to enhanced signaling through the MAPK and mTOR/Akt pathway, increased cell proliferation and reduced sensitivity to cisplatin and paclitaxel [35]. Endothelin receptor antagonists are being developed as potential chemotherapeutic agents for cancer [34]. In the ovarian tumors from the obese versus non-obese mice, DAVID functional annotation analysis revealed significant enrichment in "phospholipid binding", "regulation of apoptosis", "lipid binding", "endopeptidase activity" and "cell-cell signaling". Thus, the increase in aggressiveness, as manifested by a tripling of tumor size, in the obese $\mathrm{KpB}$ mice was accompanied by upregulation of genes involved in metabolic, apoptotic and cell signaling pathways.

Metabolic analysis revealed that 20 metabolites were identified as significantly regulated. In general, metabolomic analysis revealed that multiple metabolites contributed to separation of non-obese and obese mice with each metabolite being down-regulated in tumors derived from obese mice. Arginase 1 was the most up-regulated gene in obese tumors, which explains the lower detection of arginine concentrations. Catabolic disease states such as sepsis, injury and cancer cause an increase in arginine utilization, which can exceed normal body production, leading to arginine depletion. Arginase 1 converts L-arginine into L-ornithine and urea. Nitric oxide (NO) synthase and arginase compete for the same substrate (L-arginine); hence high arginase activity will blunt NO production, limiting potential pro-inflammatory responses necessary in tumoricidal immune responses. Indeed, arginase 1 is a marker of the M2, alternatively activated, macrophage that is often associated with more aggressive tumors [36]. Arginase also drives polyamine (such as spermidine) synthesis necessary for proliferation. Spermidine synthase in spermidine synthesis was a down-regulated gene in tumors from obese animals, perhaps in a negative feedback mechanism due to elevated delivery of ornithine generated by arginase 1 (30\% lower levels of spermidine were detected in ovarian tumors of obese mice but this did not reach statistical significance). Ornithine can also be converted to the delta-lactam 3-amino-2-piperidine, and this was significantly blunted in tumors from obese mice. Finally, arginase generates ornithine which is used to generate proline (necessary for collagen synthesis) and glutamate/glutamine. Glutamate was found at lower levels suggesting that arginase was directing ornithine production to modulate collagen synthesis in tumors derived from obese mice. AMP and arginine both activate AMP kinase (AMPK) which stimulates substrate metabolism, while arginine can also activate mTOR [37,38]. Decreased concentrations of both AMP and arginine in the ovarian tumors from obese versus nonobese mice may be a reflection of increased turnover of these metabolites in the rapidly growing tumors in the obese mice, and potential regulation of substrate metabolism.

$\mathrm{N}$-glycylproline, which had the highest VIP contributing to separation between non-obese and obese tumors, was significantly lower in obese tumors relative to non-obese tumors in $\mathrm{KpB}$ mice (Table 2, $\mathrm{p}=0.0043$ ). $\mathrm{N}$-glycylproline is an end product of collagen metabolism, but may be recycled into collagen synthesis, and this suggests a potential difference in tissue remodeling between nonobese and obese mice. Overall, Fig. 4 depicts metabolites and genes related to arginine/polyamine/collagen/glutamine metabolism that were decreased in the ovarian tumors from obese mice, suggesting that diet-induced alterations in the stromal components and 


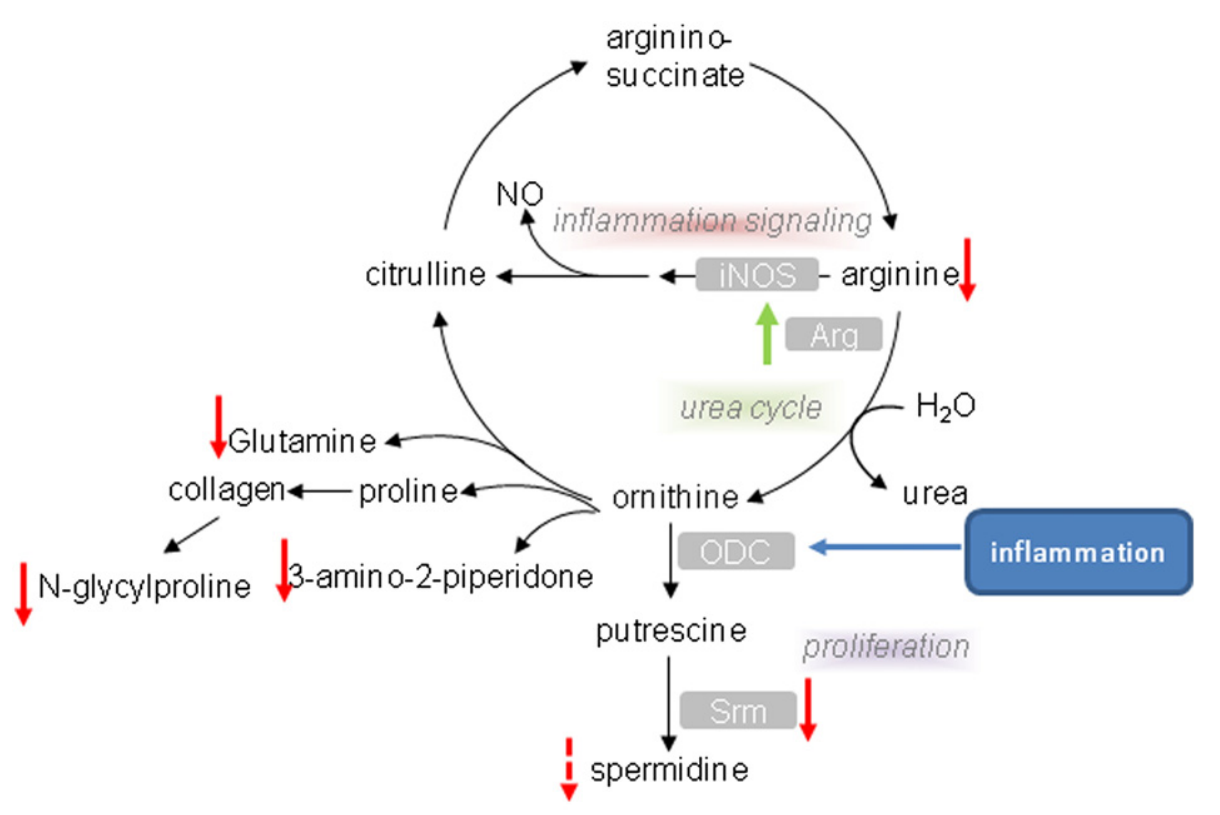

\section{iNOS: in du cible nitric oxide synthesis \\ Arg: arginase 1 \\ ODC: ornithine decarboxylase, \\ Srm: spermidine synthase \\ Significantly up or down \\ I Did not reach statistical significance}

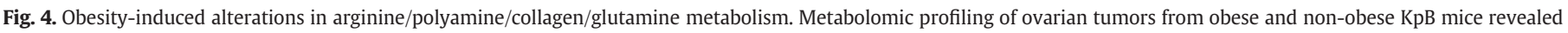

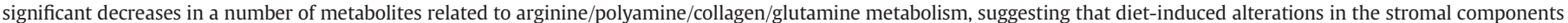
and extracellular matrix are associated with greater growth of the ovarian tumors in obese animals.

extracellular matrix are associated with greater growth of the ovarian tumors in obese animals.

Although glutathione disulfide (GSSG) and glutathione (GSH) were significantly regulated by diet, the ratio of the two (as an indicator of oxidative stress) was not significantly different between lean $(0.5-/+0.048)$ and obese $(0.45-/+0.284)$ tumors, suggesting that there was no active oxidative stress. However, a more stable marker of oxidative stress-induced DNA modification, 8-hydroxydeoxyguanosine, was detected at significantly lower concentrations in obese versus non-obese tumors. Lower concentrations of gluconolactone, an oxidized derivative of glucose, were also found in tumors from obese animals relative to lean, providing further evidence of changes in reduction-oxidation status between the ovarian tumors in the non-obese versus obese group. In sum, in ovarian tumors in obese KpB mice, there appears to be less DNA modification and markers of oxidized metabolites due to oxidative stress, suggesting that oxidative stress is not a major driver of obesity-driven tumorigenesis in the KpB mice or that compensatory mechanisms exist. Alternatively, it could be that the greater growth of ovarian tumors in the obese animals was driven by inflammatory cytokines produced in adipose tissue and distributed to the tumor through the circulation.

Lower concentrations of nucleotides (i.e. cytidine, cytosine, guanosine diphosphate (GDP), adenosine monophosphate (AMP)) may be reflective of increased cell turnover and alterations in utilization and production of these building blocks in the ovarian tumors from obese versus non-obese mice. We postulate that the observed heightened proliferation in the ovarian tumors from the obese versus non-obese mice, as evidenced by a tripling of tumor size, may result in the increased consumption of nucleotides. In the genomic analysis, we also found a 3-fold increase in ectonucleoside triphosphate diphosphohydrolase. This enzyme catalyzes the breakdown of multi-phosphated nucleotides (i.e. ATP, ADP, etc.) and removes free nucleotides and upstream compounds like AMP and GDP, all of which were significantly decreased in the ovarian tumors from the obese mice. In addition, low AMP detected in the ovarian tumors from obese mice suggests possible elevations in anabolic, ATP-burning processes such as lipid synthesis as well as protein, RNA and DNA synthesis.

5-Hydroxyindoleacetic acid (5HIAA) was significantly lower in obese versus non-obese tumors. 5HIAA is a breakdown product of serotonin. Interestingly, the serotonin transporter solute carrier family 6 member 4 (Slc6a4) was upregulated 5.4 fold by obesity. In addition to its function as a neurotransmitter in the central nervous system, increasing evidence suggests that peripheral serotonin may have proproliferative and anti-apoptotic effects and act as a mitogen in cancer cells $[39,40]$; hence, the obesity-mediated regulation of serotonin is of interest.

The catecholamine metabolites, vanillactic acid and phenylethanolamine, were lower in ovarian tumors derived from obese animals. Catecholamines, including epinephrine and norephinephrine, are known to regulate lipolysis [41]. Several studies report that catecholamine responses are blunted in obese versus non-obese individuals at rest and in response to physical activity, suggestive of decreased sympathetic nervous system activity [41]. A decrease in the catecholamine response in the obese mice could lead to reductions in lipolysis and an increase in fat stores that could be advantageous for cancer cell growth.

Succinic acid and glutamate were also significantly decreased by obesity in tumors (Table $2, p=0.0465$ and $p=0.0318$ ). Succinate is a metabolite of the tricarboxylic acid cycle (TCA) cycle and an electron donor to complex II (Succinate-Q oxidoreductase) in oxidative metabolism. Glutamate is also the metabolic intermediate of glutaminolysis, 
which would feed into the TCA cycle upstream of succinic acid at alphaketoglutarate. Interestingly, fructose-6-phosphate did not reach statistical significance (non-obese vs. obese ratio $1.62, \mathrm{p}=0.0684$ ) but contributed to principle component analysis variance (VIP was 1.67). Fructose 6-phosphate is an important intermediate in glycolysis. Taken together, low AMP, succinate, glutamate, and fructose 6phosphate suggest that $\mathrm{KpB}$ tumors in obese mice have a substantially altered metabolic phenotype compared to tumors that have arisen in non-obese controls. We are currently investigating the role of glycolysis and oxidative metabolism, along with AMPK and mTOR signaling, in ovarian cancers from obese and non-obese patients.

Finally, cytidine is a precursor of cytodinetriphosphate, which is needed to create phosphatidylcholine (PC) and phosphatidylethanolamine. Interestingly, lysoPC (16:1(9Z)) was also downregulated in the ovarian tumors from obese versus non-obese mice. Lysophospholipids (LPLs) can play a role in signaling through G-protein coupled receptors, and are a readily accessible fat source for cancer cells [42]. LPLs are generated via inflammatory-responsive phospholipase A (PLA) activity, suggesting that there may be altered inflammatory signaling between non-obese and obese tumors, which is currently being explored. In our genomic analysis, significant enrichment was found in "phospholipid binding" in the ovarian tumors from the obese mice, potentially corresponding to increased utilization of lysophospholipids in the setting of obesity and depletion of cytidine and lysoPC.

In conclusion, we demonstrate that the obese state can promote tumor progression in the $\mathrm{KpB}$ mouse model of serous $\mathrm{OC}$, resulting in genomic and metabolic differences between tumors arising in the obese versus non-obese state. Our work suggests that the metabolic consequences of obesity may be crucial in the pathogenesis of OC, resulting in biologically distinct cancers than those that arise in normal weight women. This may have important implications for the treatment of this disease, such that obesity status may be a critical factor in the individualization of management strategies. Further work will be focused on the investigation of the identified obesity-dependent metabolic biomarkers as well as potential novel targets of treatment that may be specific to obesity-driven OCs.

\section{Conflict of interest statement}

The authors declare that there are no conflicts of interest.

\section{Appendix A. Supplementary data}

Supplementary data to this article can be found online at http://dx. doi.org/10.1016/j.ygyno.2013.12.026.

\section{References}

[1] Calle EE, Rodriguez C, Walker-Thurmond K, Thun MJ. Overweight, obesity, and mortality from cancer in a prospectively studied cohort of U.S. adults. N Engl J Med 2003;348(17):1625-38.

[2] Jemal A, Siegel R, Xu J, Ward E. Cancer statistics. CA Cancer J Clin 2010;60(5):277-300.

[3] Khandekar MJ, Cohen P. Spiegelman BM. Molecular mechanisms of cancer development in obesity. Nat Rev Cancer 2011;11(12):886-95 [Epub 2011/11/25].

[4] Delort L, Kwiatkowski F, Chalabi N, Satih S, Bignon YJ, Bernard-Gallon DJ. Central adiposity as a major risk factor of ovarian cancer. Anticancer Res 2009;29(12):5229-34

[5] Pavelka JC, Brown RS, Karlan BY, Cass I, Leuchter RS, Lagasse LD, et al. Effect of obesity on survival in epithelial ovarian cancer. Cancer 2006;107(7):1520-4.

[6] Olsen CM, Green AC, Whiteman DC, Sadeghi S, Kolahdooz F, Webb PM. Obesity and the risk of epithelial ovarian cancer: a systematic review and meta-analysis. Eur J Cancer 2007;43(4):690-709.

[7] Leitzmann MF, Koebnick C, Danforth KN, Brinton LA, Moore SC, Hollenbeck AR, et al. Body mass index and risk of ovarian cancer. Cancer 2009;115(4):812-22.

[8] Guh DP, Zhang W, Bansback N, Amarsi Z, Birmingham CL, Anis AH. The incidence of co-morbidities related to obesity and overweight: a systematic review and metaanalysis. BMC Public Health 2009;9:88.

[9] Lahmann PH, Cust AE, Friedenreich CM, Schulz M, Lukanova A, Kaaks R, et al. Anthropometric measures and epithelial ovarian cancer risk in the European Prospective Investigation into Cancer and Nutrition. Int J Cancer 2010;126(10):2404-15.

[10] Schouten LJ, Goldbohm RA, van den Brandt PA. Height, weight, weight change, and ovarian cancer risk in the Netherlands cohort study on diet and cancer. Am J Epidemiol 2003;157(5):424-33 [Epub 2003/03/05].
[11] Fairfield KM, Willett WC, Rosner BA, Manson JE, Speizer FE, Hankinson SE. Obesity, weight gain, and ovarian cancer. Obstet Gynecol 2002;100(2):288-96 [Epub 2002/08/02].

[12] Chionh F, Baglietto L, Krishnan K, English DR, MacInnis RJ, Gertig DM, et al. Physical activity, body size and composition, and risk of ovarian cancer. Cancer Causes Control 2010;21(12):2183-94 [Epub 2010/09/10]

[13] Rodriguez C, Calle EE, Fakhrabadi-Shokoohi D, Jacobs EJ, Thun MJ. Body mass index, height, and the risk of ovarian cancer mortality in a prospective cohort of postmenopausal women. Cancer Epidemiol Biomarkers Prev 2002;11(9):822-8 [Epub 2002/09/12].

[14] Lubin F, Chetrit A, Freedman LS, Alfandary E, Fishler Y, Nitzan H, et al. Body mass index at age 18 years and during adult life and ovarian cancer risk. Am J Epidemiol 2003;157(2):113-20 [Epub 2003/01/11].

[15] Engeland A, Tretli S, Bjorge T. Height, body mass index, and ovarian cancer: a followup of 1.1 million Norwegian women. J Natl Cancer Inst 2003;95(16):1244-8.

[16] Reeves GK, Pirie K, Beral V, Green J, Spencer E, Bull D. Cancer incidence and mortality in relation to body mass index in the Million Women Study: cohort study. BM] 2007;335(7630):1134 [Epub 2007/11/08].

[17] Yang HS, Yoon C, Myung SK, Park SM. Effect of obesity on survival of women with epithelial ovarian cancer: a systematic review and meta-analysis of observational studies. Int J Gynecol Cancer 2011;21(9):1525-32 [Epub 2011/11/15].

[18] Protani MM, Nagle CM, Webb PM. Obesity and ovarian cancer survival: a systematic review and meta-analysis. Cancer Prev Res (Phila) 2012;5(7):901-10 [Epub 2012/05/23].

[19] Ovarian cancer and body size: individual participant meta-analysis including 25,157 women with ovarian cancer from 47 epidemiological studies. PLoS Med 2012;9(4): e1001200 [Epub 2012/05/19].

[20] Engeland A, Bjorge T, Selmer RM, Tverdal A. Height and body mass index in relation to total mortality. Epidemiology 2003;14(3):293-9 [Epub 2003/07/16].

[21] Szabova L, Yin C, Bupp S, Guerin TM, Schlomer JJ, Householder DB, et al Perturbation of $\mathrm{Rb}, \mathrm{p} 53$, and Brca1 or Brca2 cooperate in inducing metastatic serous epithelial ovarian cancer. Cancer Res 2012;72(16):4141-53 [Epub 2012/05/24].

[22] Yang YH, Dudoit S, Luu P, Lin DM, Peng V, Ngai J, et al. Normalization for cDNA microarray data: a robust composite method addressing single and multiple slide systematic variation. Nucleic Acids Res 2002;30(4):e15 [Epub 2002/02/14].

[23] Hosack DA, Dennis Jr G, Sherman BT, Lane HC, Lempicki RA. Identifying biological themes within lists of genes with EASE. Genome Biol 2003;4(10):R70 [Epub 2003/10/02]

[24] Pan L, Qiu Y, Chen T, Lin J, Chi Y, Su M, et al. An optimized procedure for metabonomic analysis of rat liver tissue using gas chromatography/time-offlight mass spectrometry. J Pharm Biomed Anal 2010;52(4):589-96 [Epub 2010/02/27].

[25] Qiu Y, Cai G, Su M, Chen T, Zheng X, Xu Y, et al. Serum metabolite profiling of human colorectal cancer using GC-TOFMS and UPLC-QTOFMS. J Proteome Res 2009;8(10):4844-50 [Epub 2009/08/15].

[26] Fordahl S, Cooney P, Qiu Y, Xie G, Jia W, Erikson KM. Waterborne manganese exposure alters plasma, brain, and liver metabolites accompanied by changes in stereotypic behaviors. Neurotoxicol Teratol 2012;34(1):27-36 [Epub 2011/11/08].

[27] Yakar S, Nunez NP, Pennisi P, Brodt P, Sun H, Fallavollita L, et al. Increased tumor growth in mice with diet-induced obesity: impact of ovarian hormones. Endocrinology 2006;147(12):5826-34 [Epub 2006/09/09].

[28] Ford NA, Dunlap SM, Wheatley KE, Hursting SD. Obesity, independent of p53 gene dosage, promotes mammary tumor progression and upregulates the p53 regulator microRNA-504. PLoS One 2013;8(6):e68089 [Epub 2013/07/11].

[29] Cho H, Kim JH. Lipocalin2 expressions correlate significantly with tumor differentiation in epithelial ovarian cancer. J Histochem Cytochem 2009;57(5):513-21 [Epub 2009/02/04]

[30] Santin AD, Zhan F, Bellone S, Palmieri M, Cane S, Bignotti E, et al. Gene expression profiles in primary ovarian serous papillary tumors and normal ovarian epithelium: identification of candidate molecular markers for ovarian cancer diagnosis and therapy. Int J Cancer 2004;112(1):14-25 [Epub 2004/08/12].

[31] Van Dross R, Soliman E, Jha S, Johnson T, Mukhopadhyay S. Receptordependent and receptor-independent endocannabinoid signaling: a therapeutic target for regulation of cancer growth. Life Sci 2013;92(8-9):463-6 [Epub 2012/10/17].

[32] Sobhia ME, Grewal BK, Ml SP, Patel J, Kaur A, Haokip T, et al. Protein kinase C inhibitors: a patent review (2008-2009). Expert Opin Ther Pat 2013;23(10):1297-315 [Epub 2013/06/26].

[33] Szydlowska M, Roszkowska A. Expression patterns of AMP-deaminase isozymes in human hepatocellular carcinoma (HCC). Mol Cell Biochem 2008;318(1-2):1-5 [Epub 2008/05/22].

[34] Bagnato A. The endothelin axis as therapeutic target in human malignancies: present and future. Curr Pharm Des 2012;18(19):2720-33 [Epub 2012/03/07]

[35] Bagnato A, Rosano L. Understanding and overcoming chemoresistance in ovarian cancer: emerging role of the endothelin axis. Curr Oncol Rep 2012;19(1):36-8 [Epub 2012/02/14].

[36] Johnson AR, Milner JJ, Makowski L. The inflammation highway: metabolism accelerates inflammatory traffic in obesity. Immunol Rev 2012;249(1):218-38 [Epub 2012/08/15].

[37] Kong X, Tan B, Yin Y, Gao H, Li X, Jaeger LA, et al. L-Arginine stimulates the mTOR signaling pathway and protein synthesis in porcine trophectoderm cells. J Nutr Biochem 2012;23(9):1178-83 [Epub 2011/12/06].

[38] Kim J, Song G, Wu G, Gao H, Johnson GA, Bazer FW. Arginine, leucine, and glutamine stimulate proliferation of porcine trophectoderm cells through the MTOR-RPS6K- 
RPS6-EIF4EBP1 signal transduction pathway. Biol Reprod 2013;88(5):113 [Epub 2013/03/15]

[39] Mohammad-Zadeh LF, Moses L, Gwaltney-Brant SM. Serotonin: a review. J Vet Pharmacol Ther 2008;31(3):187-99 [Epub 2008/05/13].

[40] Liang C, Chen W, Zhi X, Ma T, Xia X, Liu H, et al. Serotonin promotes the proliferation of serum-deprived hepatocellular carcinoma cells via upregulation of FOXO3a. Mol Cancer 2013;12:14 [Epub 2013/02/20].
[41] Zouhal H, Lemoine-Morel S, Mathieu ME, Casazza GA, Jabbour G. Catecholamines and obesity: effects of exercise and training. Sports Med 2013;43(7):591-600 [Epub 2013/04/25]

[42] Kamphorst JJ, Cross JR, Fan J, de Stanchina E, Mathew R, White EP, et al. Hypoxic and Ras-transformed cells support growth by scavenging unsaturated fatty acids from lysophospholipids. Proc Natl Acad Sci U S A 2013;110(22):8882-7 [Epub 2013/05/15]. 